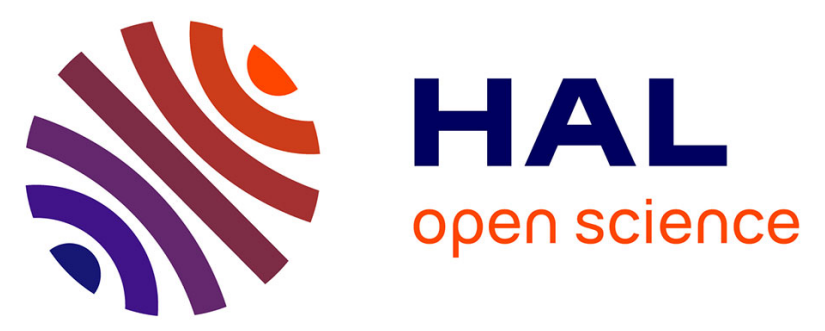

\title{
Nanoscale Accessible Porosity as a Key Parameter Depicting the Topological Evolution of Organic Porous Networks
}

Jeremie Berthonneau, Olivier Grauby, Isabelle Jolivet, François Gelin, Nicolas

Chanut, Yann Magnin, Roland J.-M. Pellenq, Daniel Ferry

\section{To cite this version:}

Jeremie Berthonneau, Olivier Grauby, Isabelle Jolivet, François Gelin, Nicolas Chanut, et al.. Nanoscale Accessible Porosity as a Key Parameter Depicting the Topological Evolution of Organic Porous Networks. Langmuir, inPress, 10.1021/acs.langmuir.0c03519 . hal-03211810

\author{
HAL Id: hal-03211810 \\ https://hal.science/hal-03211810
}

Submitted on 29 Apr 2021

HAL is a multi-disciplinary open access archive for the deposit and dissemination of scientific research documents, whether they are published or not. The documents may come from teaching and research institutions in France or abroad, or from public or private research centers.
L'archive ouverte pluridisciplinaire HAL, est destinée au dépôt et à la diffusion de documents scientifiques de niveau recherche, publiés ou non, émanant des établissements d'enseignement et de recherche français ou étrangers, des laboratoires publics ou privés. 


\title{
Nanoscale accessible porosity as a key parameter
}

\section{depicting the topological evolution of organic}

\author{
porous networks
}

Jeremie Berthonneau ${ }^{1}$, Olivier Grauby ${ }^{1}$, Isabelle C. Jolivet ${ }^{2}$, François Gelin ${ }^{2}$, Nicolas

Chanut $^{3}$, Yann Magnin ${ }^{3}$, Roland J.-M. Pellenq ${ }^{1,3}$, and Daniel Ferry ${ }^{l, ~ *}$

${ }^{1}$ Aix-Marseille Univ, CNRS, CINaM, 13009 Marseille, France

${ }^{2}$ Total E\&P Research \& Development, CSTJF - Avenue Larribau, 64018 Pau Cedex, France

${ }^{3}$ MultiScale Materials Science for Energy and Environment, CNRS/MIT/Aix-Marseille University Joint Laboratory at Massachusetts Institute of Technology, Cambridge, Massachusetts 02139, USA

\begin{abstract}
A significant part of the hydrocarbons contained in source rocks remains confined within the organic matter - called kerogen - from where they are generated. Understanding the sorption and transport properties of confined hydrocarbons within the kerogens is, therefore, paramount to predict production. Specifically, knowing the impact of thermal maturation on the evolution of the organic porous network is key. Here, we propose an experimental procedure to study the
\end{abstract}


interplay between the chemical evolution and the structural properties of the organic porous network at the nanometer scale. First, the organic porous networks of source rock samples, covering a significant range of natural thermal maturation experienced by the Vaca Muerta formation (Neuquén basin, Argentina), are physically reconstructed using bright field electron tomography. Their structural description allows us to measure crucial parameters such as the porosity, specific pore volume and surface area, aperture and cavity size distributions, and constriction. In addition, a model-free computation of the topological properties (effective porosity, connectivity, and tortuosity) is conducted. Overall, we document a general increase of the specific pore volume with thermal maturation. This controls the topological features depicting increasing accessibility to alkane molecules, sensed by the evolution of the effective porosity. Collectively, our results highlight the input of bright field electron tomography in the study of complex disordered amorphous porous media, especially to describe the interplay between structural features and transport properties of confined fluids.

\section{INTRODUCTION}

The production of hydrocarbons from hydraulic fracturing wells in source rock formation depends on three factors: the creation of fracture networks reaching the confined hydrocarbons, the ability to maintain these fractures opened, and the intrinsic fluid sorption and transport properties of the materials storing hydrocarbons. ${ }^{1-5}$ While the first two factors may be optimized by engineering strategies, the latter depends solely on the material physical chemistry. At the molecular scale, hydrocarbons are generated and stored within organic agglomerates, typically referred to as kerogens, composed of an amorphous porous carbon skeleton and dispersed in a fine-grained mineral matrix. ${ }^{6}$ The chemical composition of the carbon skeleton (carbon hybridization, functional groups, oxygen and hydrogen content) evolves through thermal maturation induced by geological burial. ${ }^{7}$ Realistic atomistic-scale models of kerogens have 
recently been proposed ${ }^{8,9}$ as a means to simulate the nano-structural arrangement of the carbon skeletons and their atoms hybridization at different thermal maturation. The nanoporous networks hence modelized, were evidenced to be responsible for the significant adsorption of hydrocarbons ${ }^{10,11}$, the breakdown of continuum hydrodynamics ${ }^{10}$, the occurrence of selfdiffusion governed transport regimes ${ }^{12-14}$, and the presence of interfacial wetting effects..$^{15}$ These results contributed greatly to the physical understanding of the fast productivity decline of hydrocarbon production wells of source rocks formations. ${ }^{2,4,5}$ Such studies, however, only accounted for nanoscale structural pores (diameter $\emptyset<2 \mathrm{~nm}$ ) of the carbon skeleton, which only constitute the lower bound of the pore size distributions described in the literature. Considering the different sizes of pores making up organic porous networks, as experimentally probed in scanning electron microscopy ${ }^{16-18}$, small-angle X-ray and neutron scattering ${ }^{19-22}$, and gas adsorption ${ }^{21,23,24}$, is paramount to cover the mechanisms affecting hydrocarbon production from source rocks.

From an experimental perspective, the analysis of gas adsorption isotherms demonstrated that the thermal maturity of the organic matter affects the pore volume and specific surface area. ${ }^{21,23,24}$ Analyses of gas adsorption measurements also allows for the determination of the pore size distribution (PSD), assuming well-defined and regular pore morphology (slit, cylinder, sphere), but do not provide any information on the network's topology. Specifically, the impact of thermal maturation on network's constriction, accessibility, and tortuosity remains unknown. However, this knowledge is crucial as these parameters have a significant impact on both sorption and transport of fluids in porous networks. ${ }^{2,23}$ To this end, the recent developments of bright-field electron tomography ${ }^{27}$ offer a promising method for 3D imaging of pores with diameters of at least a few tenths of nanometers. ${ }^{28-30}$ The physically reconstructed 3D networks can be analyzed numerically to determine the structural and topological properties at the mesoscale (from 2 to $50 \mathrm{~nm}$ ). ${ }^{31-35}$ 
We herein combine conventional organic geochemistry with electron tomography on a set of organic-rich source rocks covering a wide span of natural thermal maturity to pinpoint its impact on the structural and topological properties of organic porous networks. The selected set of samples originated from a single source rock formation, namely the Vaca Muerta formation $^{25,26}$ (Neuquén Basin, Argentina), to minimize differences in the original kerogen composition. This geological formation is composed of a succession of shales and marls and is widely recognized as a prolific hydrocarbon producing resource. ${ }^{25}$ It is characterized by a high total organic content (TOC $=2-8 \mathrm{wt} . \%)$ and a large thermal maturity gradient running east to west. $^{25}$ The organic matter is primarily identified as type II kerogen, mainly derived from marine microorganisms and altered during early burial diagenesis. We first depict the thermal maturity range of our samples by conducting equivalent vitrinite reflectance measurements and Rock-Eval pyrolysis. We then provide a set of 3D reconstructions of the organic porous networks from each source rock sample using electron tomography with a sub-nanometer resolution. We propose a complete analysis of these networks in order to provide a detailed knowledge of their dimensional, structural, and topological parameters such as constriction, effective porosity, pore coordination, and tortuosity. This approach offers unprecedented insights into the evolution of organic porous networks with respect to thermal maturity regarding both structure and topology. Our results demonstrate that thermal evolution mainly affects the accessibility of the porous networks, which, as discussed, will have implication on the transport of hydrocarbons. The present porous network analysis hence provides a way to access the interplay between the topology and physical properties of porous solids.

\section{EXPERIMENTAL SECTION}

Organic Geochemistry. An ensemble of five source rock samples from the Vaca Muerta (VM) formation (Neuquén basin, Argentina) was provided by Total SA. Their organic 
chemistry was evaluated by Rock-Eval pyrolysis (Rock-Eval 6, Vinci Technologies) and equivalent vitrinite reflectance $\left(\% \mathrm{R}_{\mathrm{eq}}\right)$ using standard organic petrology technique. ${ }^{36}$ The vitrinite reflectance values reported in Table 1 evidence the evolution of thermal maturity of the studied samples in the $0.92-1.82 \% \mathrm{R}_{\mathrm{eq}}$ range. Geochemical characteristics such as free hydrocarbons (free $\mathrm{HC}$ ), hydrogen index $(\mathrm{HI})$, and oxygen index (OI), confirming this trend, were deduced from the pyrograms (see the detailed procedure in Supporting Information, SI). ${ }^{37}$ The projection of the HIs allows for the estimation of an "onset" hydrogen index $\left(\mathrm{HI}_{0}\right)$ of the source rock formation, which is used to compute the transformation ratio $\left(\mathrm{TR}_{\mathrm{HI}}\right)$ of the organic matter, evolving here from 71.5 to $97.5 \%$ (Table 1). Our set of source rock samples therefore covers a significant range of thermal maturation experienced by the Vaca Muerta formation. ${ }^{25,26}$

Table 1. Organic Geochemistry of the Set of VM Source Rock Samples from Vitrinite Reflectance and Rock-Eval Pyrolysis (See Details in SI).

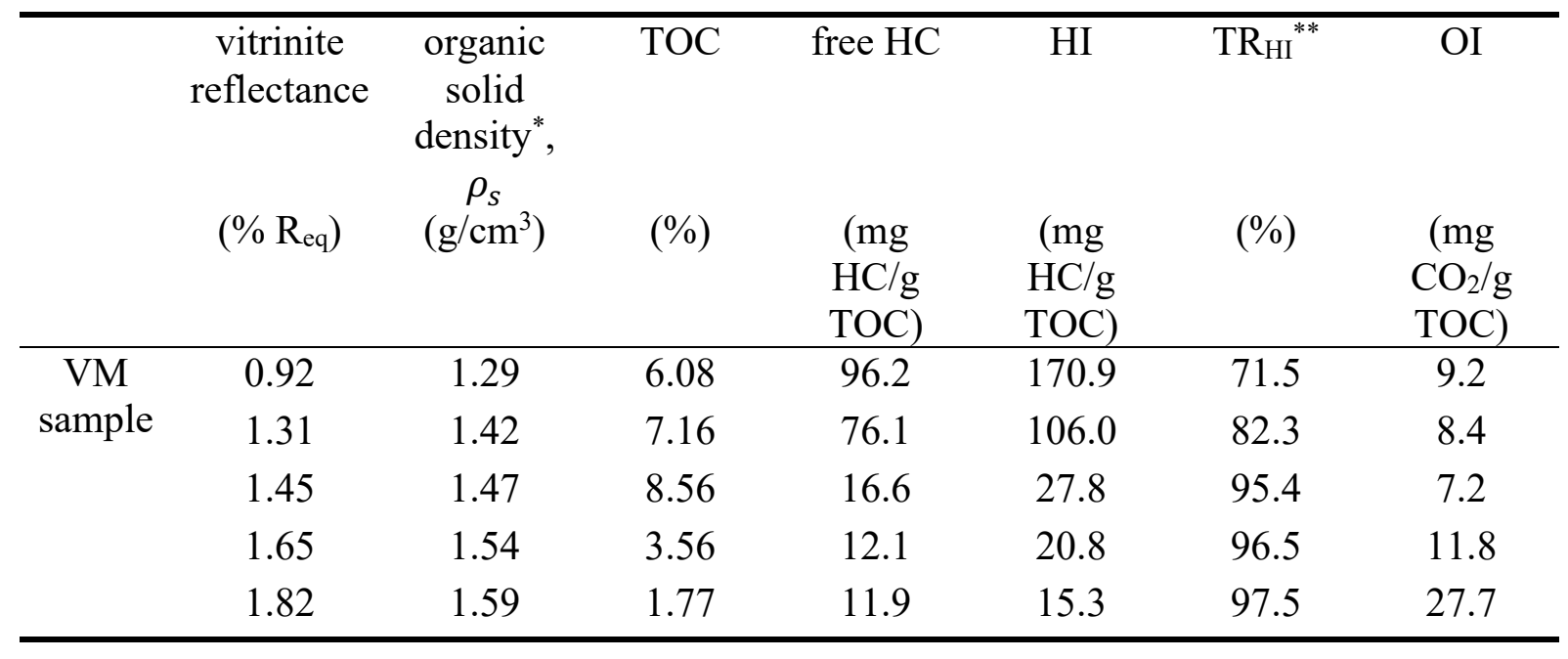

$*$ The organic solid density was calculated form the relation $\rho_{s}=0.342 \times R_{e q}+0.972$, defined in ref. 38. ${ }^{*}$ The transformation ratio $\left(\mathrm{TR}_{\mathrm{HI}}\right)$ was deduced from a $\mathrm{HI}_{0}=600 \mathrm{mg} \mathrm{HC} / \mathrm{g} \mathrm{TOC}$.

Sample Preparation. Polished pieces of each source rock sample (Figure 1a) were subjected to a flux of argon in a flat ion milling machine (1060SEM Fischione) for 2 cycles of 30 minutes 
at $5 \mathrm{kV}$ with an incident angle of $5^{\circ}$, followed by 3 cycles of 30 minutes at $5 \mathrm{kV}$ with an incident angle of $2^{\circ}$. The micro-texture was then imaged by a mosaic of backscattered electron (BSE) micrographs (Figure 1b) in a scanning electron microscope (SEM Crossbeam 540 Zeiss) operating with a $20 \mathrm{kV}$ accelerating voltage. Details of these mosaics allowed us to localize large filamentous agglomerates of organic matter (Figure 1c) within the inorganic matrix of the source rock samples. The milled samples were then placed in a FEI Helios NanoLab 660 focused ion beam (FIB, $\mathrm{Ga}^{+}$beam) to produce one FIB thin section per VM sample. The thinning process was conducted down to a thickness of $\sim 100 \mathrm{~nm}$ to allow electron transparency in subsequent transmission electron microscopy (TEM) measurements. ${ }^{39}$ The extraction procedure was uniformly applied on the filamentous organic matter agglomerates (kerogen) previously identified (Figure 1c), as they constitute the main contributors of organic porosity in source rocks. ${ }^{16,17,39,40}$
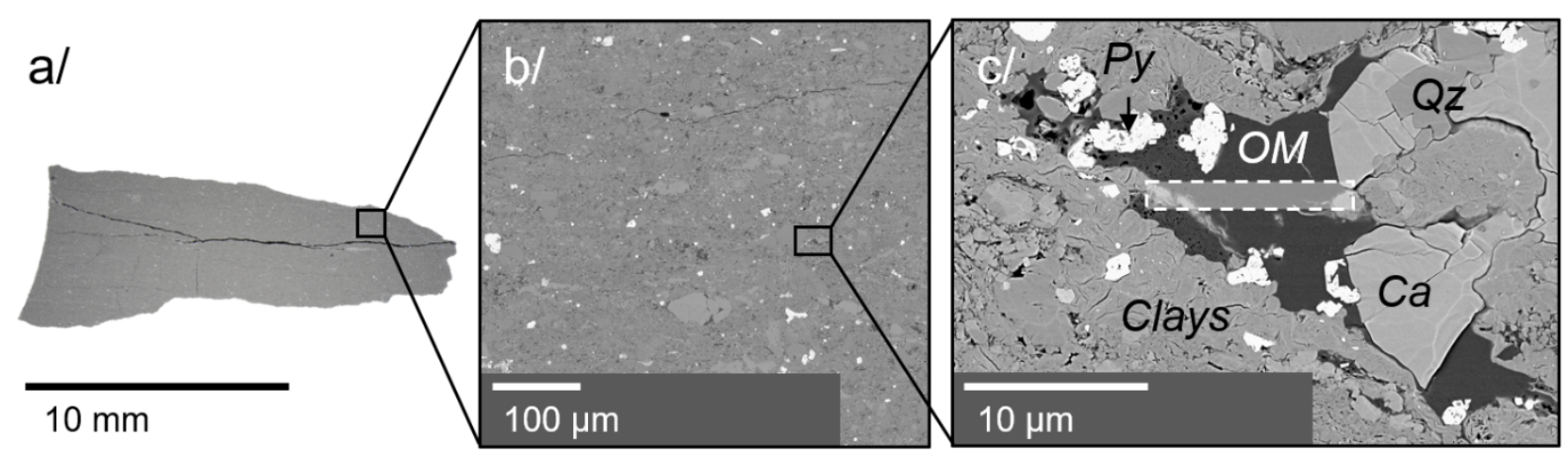

Figure 1. Localization of organic matter agglomerates for FIB thin section procedure. (a) Macroscopic view of the sample VM 0.92 (Vaca Muerta, $0.92 \% \mathrm{R}_{\mathrm{eq}}$ ) under reflective optical microscope. (b) Mosaic of backscattered electron (BSE) micrographs of the microtexture. (c) Details of the BSE mosaic displaying an agglomerate of organic matter (OM, very dark grey) surrounded by inorganic inclusions (Qz: quartz; Ca: calcite; Clays: clay minerals; Py: pyrite). The dotted white box corresponds to the volume extracted by FIB thin sectioning. 
Electron Tomography. The FIB thin sections $\left(10 \times 5 \mu \mathrm{m}^{2}\right.$, Figure $\left.2 \mathrm{a}\right)$ were observed under a transmission electron microscope (TEM, Jeol JEM-2010) fitted with a $\mathrm{LaB}_{6}$ electron gun, under a $200 \mathrm{kV}$ accelerating voltage, and assisted by the Digital Micrograph software (GATAN, Image suite ${ }^{\circledR}$ v.2.31). Bright-field imaging of the thin sections (Figure 2b, c) reveals spongelike organic matter with pores varying considerably in size and spatial density. Some locations display isolated macropores (diameter $\emptyset>50 \mathrm{~nm}$, Figure $2 \mathrm{~b}$ and 1c), while other parts only contain heterogeneous nano/mesopore networks $(\varnothing<50 \mathrm{~nm}$, Figure $2 \mathrm{c})$. These nano/mesopore networks constitute the cornerstone of our approach as, in contrast to the macropores, they are present in the whole set of thin sections. It is noteworthy that such porosity is nearly unresolved by conventional imaging and tomography techniques. ${ }^{41,42}$ The use of electron tomography ${ }^{27}$ with a subnanometric resolution is therefore essential for its characterization. The yellow box in Figure 2c displays a typical location and size of the region of interests (ROI) targeted for electron tomography experiments.
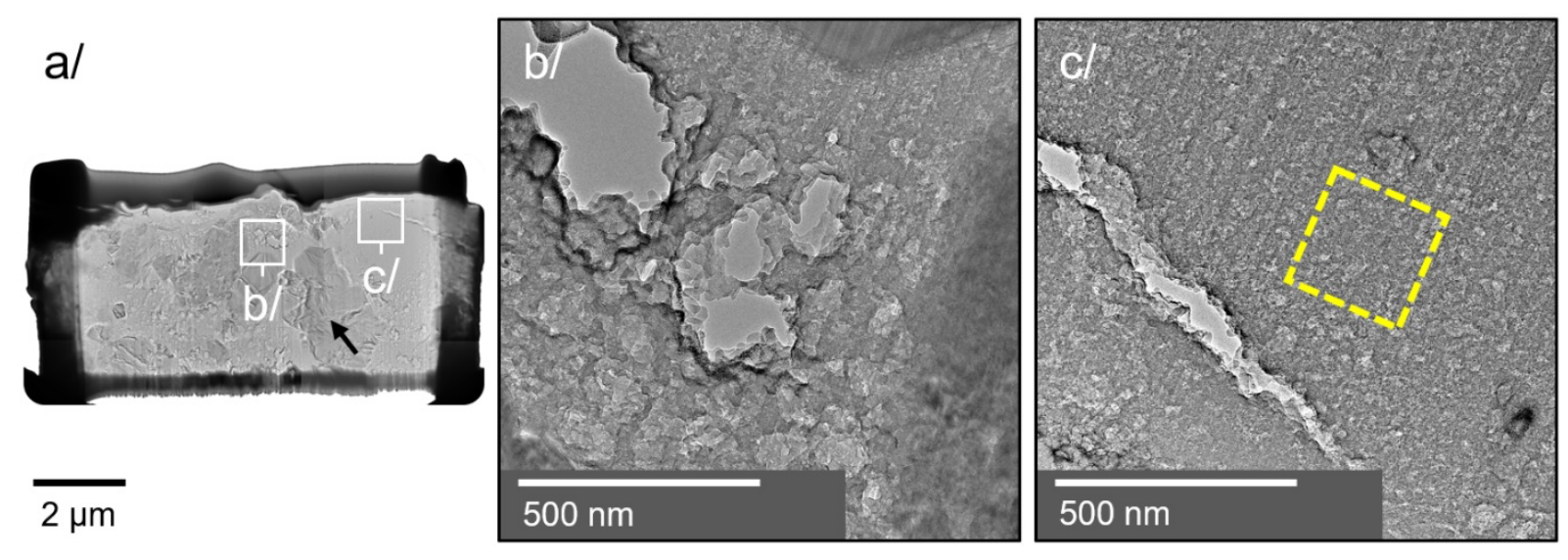

Figure 2. Heterogeneous porosity of source rock's organic matter. (a) Mosaic of lowmagnification TEM images showing the whole FIB thin section of an organic matter agglomerate from VM 1.65. The very dark areas surrounding the thin section correspond to Pt, deposited to ensure the mechanical rigidity; the dark grey areas correspond to inorganic inclusions (indicated by a black arrow); and the light grey regions to porous organic matter. (b) 
TEM image showing porous organic matter with pores size $(\varnothing)$ ranging from few tenths of nanometers to more than $200 \mathrm{~nm}$. (c) TEM image displaying a crack in a dense region of heterogeneous nano/mesopore networks $(\varnothing<50 \mathrm{~nm})$. The yellow dotted box indicates the ROI considered for electron tomography acquisition.

Electron tomography ${ }^{27}$ experiments were carried out in regions of organic matter containing porous networks with pore sizes less than $50 \mathrm{~nm}$ (Figure 3). Tilt series of 2D projections were recorded with a CCD camera (GATAN, Ultrascan 1000XP) at a magnification of 30000 over an angular range from -50 to $+50^{\circ}$ relative to the electron beam with an angular step of $1^{\circ}$. The tilt series of 101 2D projections were first aligned (translation + rotation) with a crosscorrelation procedure implemented in the software before being reconstructed in Fourier space by the weighted back-projection (WBP) method. As the reconstruction procedure generates a noise affecting the original signal, an image filtering procedure was developed. It relies on the comparison between a reference image (i.e., the original image acquired at $0^{\circ}$ ) and the summation of the reconstruction according to the $z$ direction, on which a filter was applied. We found that the noise generated by the tomogram reconstruction calculations mainly affects the intra class variance, i.e., the variation of grey level within a pore, or similarly within the solid (here, the solid corresponds to the kerogens' carbon skeleton). A “nonlocal mean denoising" filter was therefore used to minimize this noise. ${ }^{43}$ The filter parameters were optimized to maximize the peak signal-to-noise ratio (PSNR, see ref 44) between the reference image and the filtered one, for each reconstruction. A segmentation of the filtered tomogram's grey level histogram was then performed using the "Otsu thresholding" method ${ }^{45}$ to discriminate the pore network from the solid. This method has already been successfully applied in the determination of porous networks ${ }^{46}$ and avoids any user setting choices in the segmentation process as required by watershed algorithms, which are also largely used. ${ }^{47}$ This entire procedure was 
applied to the four tilt series of 2D projections acquired on each FIB thin section to account for the internal variation of pore size and spatial density in the networks (Figure 2). The 20 resulting segmented tomograms contain stacks of binary images with dimensions $(x \times y \times z)$ varying between $245 \times 245 \times 87.5 \mathrm{~nm}^{3}$ and $245 \times 245 \times 140 \mathrm{~nm}^{3}$, with a voxel size of $(0.35)^{3} \mathrm{~nm}^{3}$.

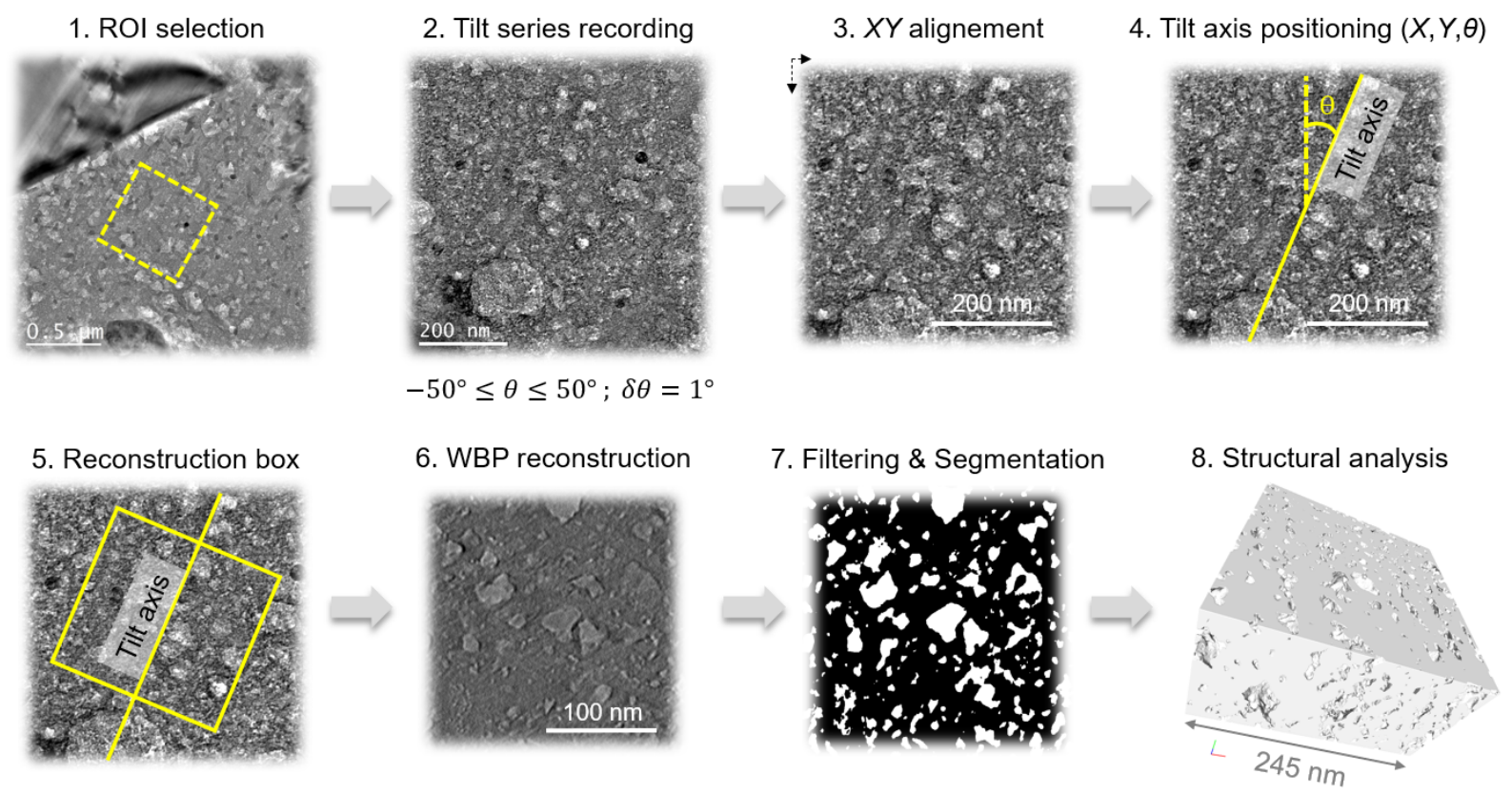

Figure 3. Electron tomography workflow allowing for visualizing and analyzing the structure of the organic porous networks (illustrations from sample VM 1.31).

Structural Analysis. Statistical analyzes were conducted on the 20 binary tomograms to describe the global, dimensional, and topological characteristics of the organic porous networks. We specifically determined:

- global information such as porosity ( $\varphi$, only accounting for pore sizes smaller than 50 $\mathrm{nm})$, chord length distribution (CLD), and specific surface area $\left(S_{s p}\right)$;

- dimensional information such as specific pore volume $\left(V_{p}\right)$, specific mesopore volume $\left(V_{\text {meso }}\right)$, aperture and cavity sizes distributions; 
- topological information such as constriction $(\beta)$, effective porosity $\left(\varphi_{\text {eff }}\right)$, pores coordination $(Z)$, and tortuosity $(\tau)$.

These determinations were carried out using the public-domain software $\mathrm{iMorph}^{48,49}$ and ImageJ. ${ }^{50}$ First, $V_{p}$ was computed by summing the pore voxels from the binary tomograms, and the organic porosity $\varphi$ was calculated as

$$
\varphi=\frac{V_{p}}{V_{t}}=\frac{V_{p}}{V_{p}+V_{s}}
$$

where $V_{t}$ is the tomogram volume and $V_{s}$ is the solid volume.

The chord length distribution (CLD) was evaluated by propagating more than $10^{6}$ segments of random origin and direction in the pore volume of the tomogram ${ }^{33,34,51}$; hence producing a histogram of the chord lengths $l$ intersecting the pores. The first statistical moment of the normalized frequency distributions, or mean chord length $\langle l\rangle$, was used as a quantitative measure of the average pore size. The specific surface $S_{s p}$ was computed from ${ }^{51}$

$$
S_{s p}=\frac{4 \varphi}{\rho_{s}(1-\varphi)\langle l\rangle}
$$

where $\rho_{s}$ is the density of the organic solid phase (Table 1).

There is no uniform pore size value in heterogeneous pore networks. They are therefore characterized by their pore size distribution (PSD). ${ }^{31,32,49}$ Here, the PSD was determined from two distinct approaches: (i) the aperture map computation and (ii) the cavity segmentation. The first approach starts with the Euclidian distance mapping of the pore network, which provides the axis of pore voxels placed at equidistance to the pore/solid interfaces. Spheres of increasing diameters are then propagated from this center axis until they reach the voxels of the solid phase (solid voxels). The diameter of the largest sphere containing pore voxels without overlapping with any solid voxels is considered as the pore size. ${ }^{49}$ This diameter is called aperture diameter and is sensitive to the pore accesses, or throats. The volumetric distribution of the aperture 
diameter was used to obtain the PSD in incremental and cumulative histograms, and the specific mesopore volume $V_{\text {meso }}(2<\emptyset<50 \mathrm{~nm})$ was calculated from this distribution.

The second approach to establish the PSD is based on a watershed segmentation algorithm. This method uses the geographical concept of watershed, where a limit is placed between two catchment basins. These separations are deduced numerically from the distance map, hence delimiting cells (or cavities) connected by throats. The volumetric distribution of the equivalent sphere (i.e., sphere having the same volume as the considered cavity) diameter of each segmented cavity is then plotted to obtain the cavity size distribution in incremental and cumulative histograms.

The aperture and cavity size distributions obtained from these approaches offer a way to quantitatively define the constriction $\beta$. Equation 3, expressed hereafter, was used to account for the variation of pores diameter between the statistically most significant aperture $(h)$ and cavity $(H)$ sizes and characterizes the ink bottle shape $\mathrm{e}^{32,35}$ at the nanometric scale

$$
\beta=\frac{h}{H}
$$

With $\beta$ a dimensionless parameter ranging from $0(h<<H)$ to $1(h=H)$. This parameter has been recently identified as crucial by molecular dynamics simulations where the diffusion of methane molecules in topology displaying important constriction does not follow the nanoDarcy equation. ${ }^{10}$ In addition, it has been noted that constricted topologies strongly further reduce the molecular flow compared to the one with constant pore diameters. Thus, computing constriction from experiments is key as it constitutes a limiting parameter in the fluid flow, and thus in gas extraction.

The impact of constriction on the pore network's accessibility was evaluated by quantifying the effective porosity $\varphi_{\text {eff }}$ : the volumetric fraction of contiguous pores with respect to increasing opening diameter. Technically, the sum of connected pore voxels was measured for each opening pore diameter, with an increment of $0.07 \mathrm{~nm}$. This approach is equivalent to the 
exploration of the pore network with a probe of increasing size. At each opening pore diameter (or probe size) increment, the corresponding effective (or accessible) porosity is recorded. It allowed us to produce percolation curves and to discern effective porosity, as well as closed porosity, at different characteristic sizes. Here, we focused on the tomogram pixel resolution $(0.35 \mathrm{~nm})$ and the transition from nanopores to mesopores $(2 \mathrm{~nm})$, but any relevant molecular probe size could be used.

The tomograms were also skeletonized using an iterative thinning algorithm implemented in ImageJ (Skeletonize 3D - BoneJ; see ref 52) to determine the total number of pore junctions $\left(n_{j}\right)$ and the number of triple $\left(n_{t}\right)$, quadruple $\left(n_{q}\right)$, and higher $\left(n_{x}\right)$ pore junctions. The average pore coordination number $(Z)$ was calculated from ${ }^{34}$

$$
Z=3 \times \frac{n_{t}}{n_{j}}+4 \times \frac{n_{q}}{n_{j}}+5 \times \frac{n_{x}}{n_{j}}
$$

with

$$
\frac{n_{x}}{n_{j}}=1-\frac{n_{t}}{n_{j}}-\frac{n_{q}}{n_{j}}
$$

Finally, the tortuosity is often considered an essential structural feature affecting the transport properties in porous media ${ }^{53}$, as it is analogous to the effective path length followed by the fluids. Statistical description of the effective path length can, however, be performed in different ways. ${ }^{34}$ Here, we generated 150000 random walkers within the pore networks and recorded their free travel distance during 4500 iterations. The free distance traveled by the walkers was divided by the Euclidian distance from their start to end points to compute the tortuosity, here called random walker tortuosity $\left(\tau_{r w}\right)$. This approach is often considered to provide a "higher bound" tortuosity ${ }^{33}$, which better accounts for the process of molecular diffusion in porous networks.

\section{RESULTS AND DISCUSSION}


Global Information. The 20 tomograms cover a volume of organic matter free of any inorganic inclusion. The segmented 3D reconstructions therefore contain two distinct phases: (i) the solid amorphous carbon skeleton (see refs 9, 12-14 for the numerical representation of such carbon skeletons); and (ii) the porous networks (with $\emptyset<50 \mathrm{~nm}$ ). The specific pore volume $V_{p}\left(\right.$ in $\left.\mathrm{cm}^{3} / \mathrm{g}\right)$ hence corresponds to the sum of the pore voxels over the mass of the carbon skeleton, determined from the organic solid density $\rho_{s}$ of the sample (Table 1) and the solid volume $V_{s}$ given by the number of voxels of the solid phase. The volumetric fraction of pore voxels in the tomograms represents the porosity $\varphi$ below $50 \mathrm{~nm}$. Figure $\mathrm{S} 1$ shows the general evolution of specific pore volume (from 0.134 to $0.228 \mathrm{~cm}^{3} / \mathrm{g}$ ) and porosity (from 14.6 to 26.5 vol. \%) in the set of samples.

An internal variability of these quantities is noted within each VM sample and is fully reported in Table S1. Thus, although the average specific pore volume of the VM 1.65 sample is $V_{p}=0.176 \mathrm{~cm}^{3} / \mathrm{g}$, it varies from 0.096 to $0.263 \mathrm{~cm}^{3} / \mathrm{g}$ on the four different tomograms recorded. This highlights the internal heterogeneity of the sample and confirms the observations previously made from the TEM images (see Figure 2 for the VM 1.65 sample). Nonetheless, the mean values (Figure S1) plead toward a tendency of increasing organic specific pore volume with thermal maturation.

Regarding these results, one may wonder to what extent the porosity imaged in electron tomography is representative, compared to the total porosity of the source rock. We confront our values of $\varphi \equiv \varphi_{<50 \mathrm{~nm}}$ with the total (i.e., the entire source rock sample) nuclear magnetic resonance (NMR) porosity $\varphi_{N M R}$, whose values were provided by Total SA for the same set of source rock samples, to answer this question. From the known TOC (in wt \%) and assuming the densities of the organic and inorganic matter $\left(\rho_{\text {org }}=1.3 \mathrm{~g} / \mathrm{cm}^{3}\right.$ and $\left.\rho_{\text {inorg }}=2.65 \mathrm{~g} / \mathrm{cm}^{3}\right)$, one can compute the volumetric proportion of organic carbon (TOC in vol \%). Then, the 
volumetric fraction of organic pores imaged by electron tomography $\left(\varphi_{\text {tomo }}\right)$ can be deduced from

$$
\left.\varphi_{\text {tomo }}=(\varphi / 100) \times \text { TOC (in vol. } \%\right)
$$

With $\varphi$ the mean value of organic porosity at a given thermal maturity (see Table $\mathrm{S} 1$ ). We found from eq. (6) that $\varphi_{\text {tomo }}$ ranges from 0.9 (VM 1.82) to 3.5 (VM 1.45) vol \%, indicating that the porosity of the organic matter probed by electron tomography represents a fraction of $7.5-27.1 \%$ of the total porosity of the source rock probed by NMR (Table 2).

Table 2. Total Organic Content (TOC) of the Source Rock Samples and Comparison between the Porosity of Organic Matter $\varphi_{\text {tomo }}$ Determined by Electron Tomography and the Total Porosity of the Source Rock Determined by Nuclear Magnetic Resonance $\varphi_{N M R}$

\begin{tabular}{|c|c|c|c|c|c|}
\hline $\begin{array}{c}\text { vitrinite } \\
\text { reflectance } \\
\left(\% \mathrm{R}_{\mathrm{eq}}\right)\end{array}$ & $\begin{array}{l}\text { TOC } \\
\text { (wt. } \\
\% \text { ) }\end{array}$ & $\begin{array}{l}\text { TOC } \\
\text { (vol. } \\
\%)\end{array}$ & $\begin{array}{c}\text { organic porosity, } \\
\varphi_{\text {tomo }} \\
(\text { vol. } \%)\end{array}$ & $\begin{array}{c}\text { total porosity, } \\
\varphi_{N M R} \\
(\text { vol. } \%)\end{array}$ & $\begin{array}{c}\varphi_{\text {tomo }} / \varphi_{N M R} \\
(\%)\end{array}$ \\
\hline 0.92 & 6.08 & 11.66 & 1.7 & 13.0 & 13.1 \\
\hline 1.31 & 7.16 & 13.59 & 2.9 & 13.5 & 21.5 \\
\hline 1.45 & 8.56 & 16.02 & 3.5 & 13.0 & 27.1 \\
\hline 1.65 & 3.56 & 7.00 & 1.5 & 10.5 & 13.9 \\
\hline 1.82 & 1.77 & 3.54 & 0.9 & 12.5 & 7.5 \\
\hline
\end{tabular}

Indeed, only a small fraction of the pores contained in the source rocks is recorded in the tomograms, i.e., those contained in the organic matter and whose sizes range from 0.35 to 50 $\mathrm{nm}$. It should be kept in mind that part of the organic porosity is unresolved by our approach, due to combined constraints of magnification and field of view in TEM. This part of the organic porosity corresponds to (i) the structural nanopores of the organic carbon skeleton ${ }^{9,12-14}$ and (ii) the macropores whose large sizes $(\emptyset>50 \mathrm{~nm})$ are more suitable for scanning electron microscopy (SEM) observations. ${ }^{16-18}$ Source rocks also contain inorganic pores in a wide variety of sizes and locations. ${ }^{16-18,24,42,54}$ They can significantly contribute to the total porosity 
measured by NMR and may have various origins such as internal cracks, spaces between inorganic particles (e.g. interparticle porosity), or space within inorganic particles such as clay minerals (e.g. intraparticle porosity). Nonetheless, our approach allows to specifically study the fraction of organic pore networks directly influencing the sorption and transport properties of kerogen generated hydrocarbons.

We then established the in-pore chord length distribution (CLD) to further characterize the relative size distribution of the imaged organic porous networks. Figure 4 displays the averaged CLDs obtained on the set of VM samples. They show similar general shapes with a slightly increasing frequency between 0.35 and $2 \mathrm{~nm}$, a slow decrement in the $2-50 \mathrm{~nm}$ range, and an abrupt decay beyond $50 \mathrm{~nm}$. Within this general trend, two extremes are observed. They are distinguished from each other by their relative frequency distribution of nano/mesopores. As shown in Figure 4, samples VM 0.92 and VM 1.65 present a higher proportion of nanopores, while VM 1.45 and VM 1.82 contain a greater fraction of mesopores. The mean pore size is given by the first statistical moment of the frequency distribution, or "mean chord length" $\langle l\rangle$, which varies from $4.3 \mathrm{~nm}$ for VM 0.92 to $7.1 \mathrm{~nm}$ for VM 1.82 (Figure $\mathrm{S} 1$ ). Knowing $\langle l\rangle$, we used eq (2) to determine $S_{s p}$ and found mean values ranging from 127.5 to $193.4 \mathrm{~m}^{2} / \mathrm{g}$ (Table S1). As already mentioned for the specific pore volume, there is a significant internal variation in the CLD (see inset of Figure 4) and thus $S_{s p}$ from the tomograms of a given sample (see Table S1), reflecting the heterogeneity of the porous network present in the organic matter. 


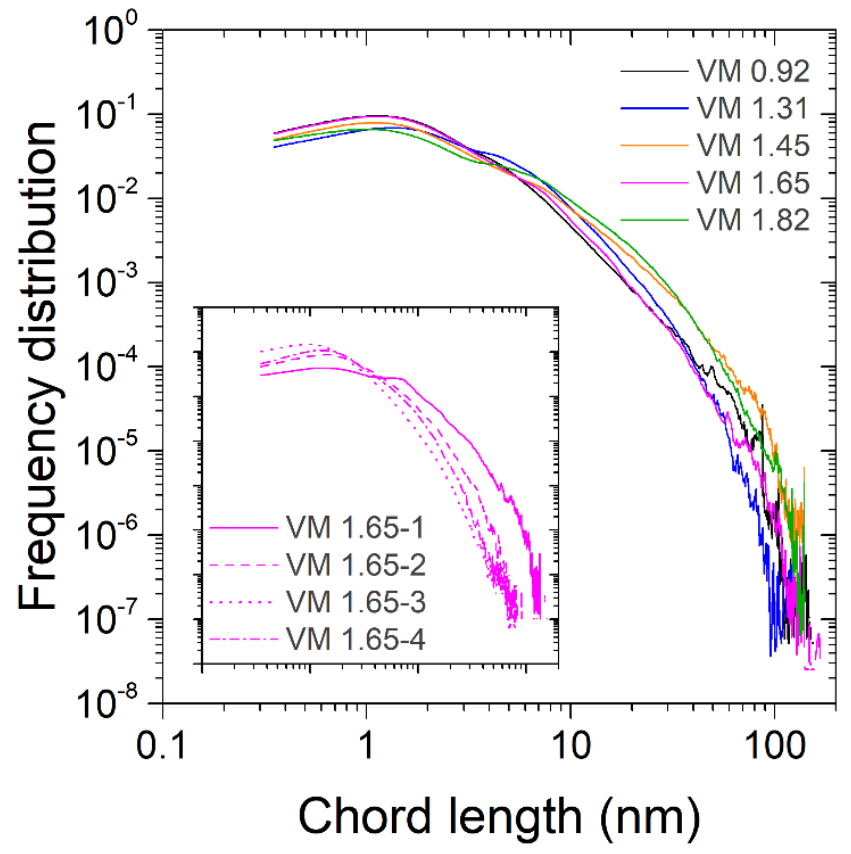

Figure 4. Mean in-pore chord length distributions (CLD) of the VM samples. Inset: CLDs obtained on the four tomograms of VM 1.65 showing the sample's heterogeneous porosity.

This description allows comparing the measured structural properties with those from other marine sedimentary formations containing type II kerogen. By knowing the TOC of a source rock sample and applying a procedure to substitute the specific surface area attributed to clay minerals (provided quantitative mineralogy is available), one can compute the organic matter's $S_{s p}$ from adsorption isotherms of bulk rock samples. ${ }^{23}$ In parallel, a sample preparation combining acid demineralization and critical-point drying allows for the direct measurement of kerogens adsorption isotherms that only need to be corrected for the residual pyrite content. $^{26,55,56}$ The published values of kerogens' $S_{s p}$ as a function of thermal maturity for a wide range of type II kerogens show that $S_{s p}$ increases by 1 order of magnitude between immature ( $\sim 50 \mathrm{~m}^{2} / \mathrm{g}$ TOC) and overmature kerogens in the dry-gas window $\left(\sim 500 \mathrm{~m}^{2} / \mathrm{g}\right.$ TOC). 21,23,26,55,56 Table S1 evidence that the $S_{s p}$ computed from the CLDs on our set of tomograms agree with the literature. Such global information, however, does not provide specific insights on the variations of the organic pore morphology and topology. 
Pore Size Distribution. We further analyze the porous networks by the characterization of their PSD. ${ }^{31,32,49}$ We first establish the PSD from the determination of the aperture diameter, as mentioned in the Experimental Section. We present, in Figure S2, the mean PSDs obtained for each thermal maturity. Each of these mean PSDs was created by the summation of the PSDs of the four tomograms acquired at a given thermal maturity (as shown in the inset of Figure S2 for the VM 1.65 sample). This procedure thus takes the local heterogeneity of these complex porous networks into account and provides a representative picture of their characteristics. Note, however, that these PSDs depict only a fraction of the total PSD, as deduced from gas adsorption isotherms, for instance. ${ }^{21,23}$ The explanation for this is threefold. First, the pixelresolution limit of the tomograms (one voxel $=0.35 \times 0.35 \times 0.35 \mathrm{~nm}^{3}$ ) prevents the accurate detection of nanopores of size smaller than $0.7 \mathrm{~nm}$ present in the sample, which would be probed by $\mathrm{CO}_{2}$ adsorption. ${ }^{21}$ Second, the selected field of view of the TEM results in tomogram size limited to about $250 \mathrm{~nm}$ sideways, which precludes recording macropores usually sensed by $\mathrm{N}_{2}$ adsorption or $\mathrm{Hg}$ intrusion porosimetry. ${ }^{21}$ Third, the gas adsorption isotherms carried out on source rocks do not differentiate organic from inorganic pores, the latter, if present, being ignored by our electron tomography approach. Despite these constraints, related to the size and resolution of the tomograms, we note a reasonable agreement with PSDs obtained from $\mathrm{N}_{2}$ adsorption isotherms for the mesopore range. ${ }^{21}$ This explains the general agreement between the $S_{s p}$ computed from the CLDs on our set of tomograms and the literature. ${ }^{21,23,26,55,56}$ Therefore, the specific mesopore volumes $V_{\text {meso }}$, corresponding to the cumulated pore (between 2 and $50 \mathrm{~nm}$ ) volumes per gram of sample, are extracted from the aperture size distributions (Table S2). The mean values of $V_{\text {meso }}$ ranges from 0.083 (VM 0.92 ) to $0.195 \mathrm{~cm}^{3} / \mathrm{g}$ (VM 1.82 ) and shows an upward trend with thermal maturation (Table 3). 
In addition to the aperture size distribution, we also computed the volumetric distribution of the watershed segmented cavities (see the Experimental Section). The cumulative histograms of the cavity size distribution as well as those from the aperture size distribution are shown in Figure 5. From this figure, we deduce that the studied organic porous networks are statistically composed of large cavities $(\sim 13.0-18.9 \mathrm{~nm})$ connected by small apertures $(\sim 4.1-7.5 \mathrm{~nm})$. This structural feature, also known as the ink bottle shape, is a potential issue regarding the interpretation of gas adsorption isotherms. In this regard, it should be noted that the VM 1.82 sample statistically presents larger apertures than the other samples.

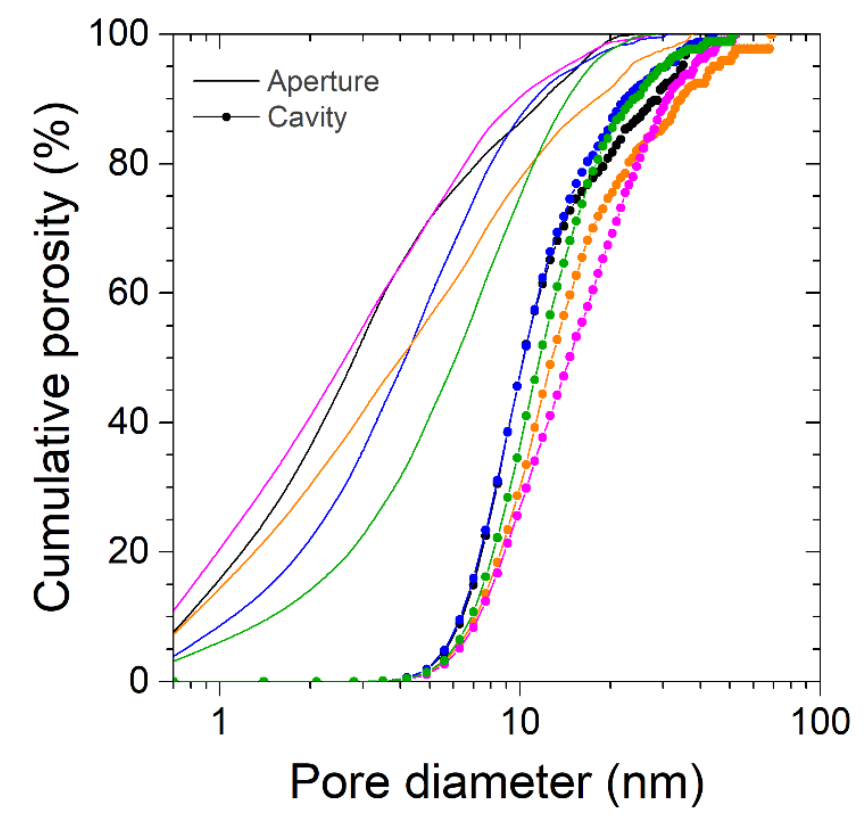

Figure 5. Cumulative histograms of the aperture (solid line) and cavity (line with symbols) size distributions of the VM samples (the color code is similar to Fig. 4).

From the distributions shown in Figure 5, we quantitatively define the constriction $(\beta)$ of the networks with the relationship given in eq 3 . Here, we consider the average aperture $(h)$ and cavity $(H)$ sizes from

$$
w=\frac{\sum_{i}\left(\frac{d V}{d w}\right)_{i} w_{i}}{\sum_{i}\left(\frac{d V}{d w}\right)_{i}}
$$


With $w$ being the aperture $h$ or cavity size $H$. The constriction is thus a dimensionless parameter ranging from 0 (closed pores) to 1 (pores with constant sizes). ${ }^{32,35} \mathrm{We}$ found that the mean constriction values vary from 0.31 (VM 1.45) to 0.43 (VM 1.82) (Table 3). All the studied porous networks hence show some ink bottle shape but to a different degree. The lowest values would induce morphological limitations for transport processes caused by the narrow opening of the pores, which will hence create some transport resistance. ${ }^{32}$ Note that this parameter, as well as the rest of the topological properties, could be influenced by the elasticity of the carbon skeleton, which was shown to vary with maturity. Indeed, while mature kerogens are assumed to be rigid, immature kerogens show noticeable deformation. ${ }^{57}$ This parameter, however, varies greatly within the set of studied tomograms (see Table S2), and no specific trend of evolution with thermal maturity is noted.

Table 3. Morphological Descriptors of the Organic Pore Networks.

\begin{tabular}{ccccc}
\hline $\begin{array}{c}\text { vitrinite } \\
\text { reflectance } \\
\left(\% \mathrm{R}_{\mathrm{eq}}\right)\end{array}$ & $\begin{array}{c}\text { mesopore volume, } \\
V_{\text {meso }} \\
\left(\mathrm{cm}^{3} / \mathrm{g}\right)\end{array}$ & $\begin{array}{c}\text { aperture size, } \\
h \\
(\mathrm{~nm})\end{array}$ & $\begin{array}{c}\text { cavity size, } \\
H \\
(\mathrm{~nm})\end{array}$ & constriction, $\beta$ \\
\hline 0.92 & 0.083 & 5.2 & 14.0 & - \\
1.31 & 0.146 & 5.5 & 13.0 & 0.37 \\
1.45 & 0.132 & 7.5 & 18.9 & 0.41 \\
1.65 & 0.102 & 4.1 & 13.2 & 0.37 \\
1.82 & 0.195 & 7.4 & 17.4 & 0.43 \\
\hline
\end{tabular}

Topology. The impact of the PSD and constriction of these networks on their accessibility to hydrocarbon molecules is assessed by quantifying the effective, or accessible, porosity $\varphi_{e f f}$. We follow the accessibility by plotting the percolation curves of each VM sample with respect to the opening pore diameter (akin to a "probe size") in Figure 6a. These curves first allow us to distinguish between closed porosity (pores isolated from the tomogram faces) and decreasingly accessible porosity (Figure 6b). We discern effective porosities at different 
characteristic sizes, such as the pixel resolution of the tomograms $(0.35 \mathrm{~nm})$ and the transition from nanopores to mesopores $(2 \mathrm{~nm})$. The values of these effective porosities $\left(\varphi_{\text {eff }}^{0.35 \mathrm{~nm}}\right.$ and $\left.\varphi_{\text {eff }}^{2 n m}\right)$ are listed in Table S3.
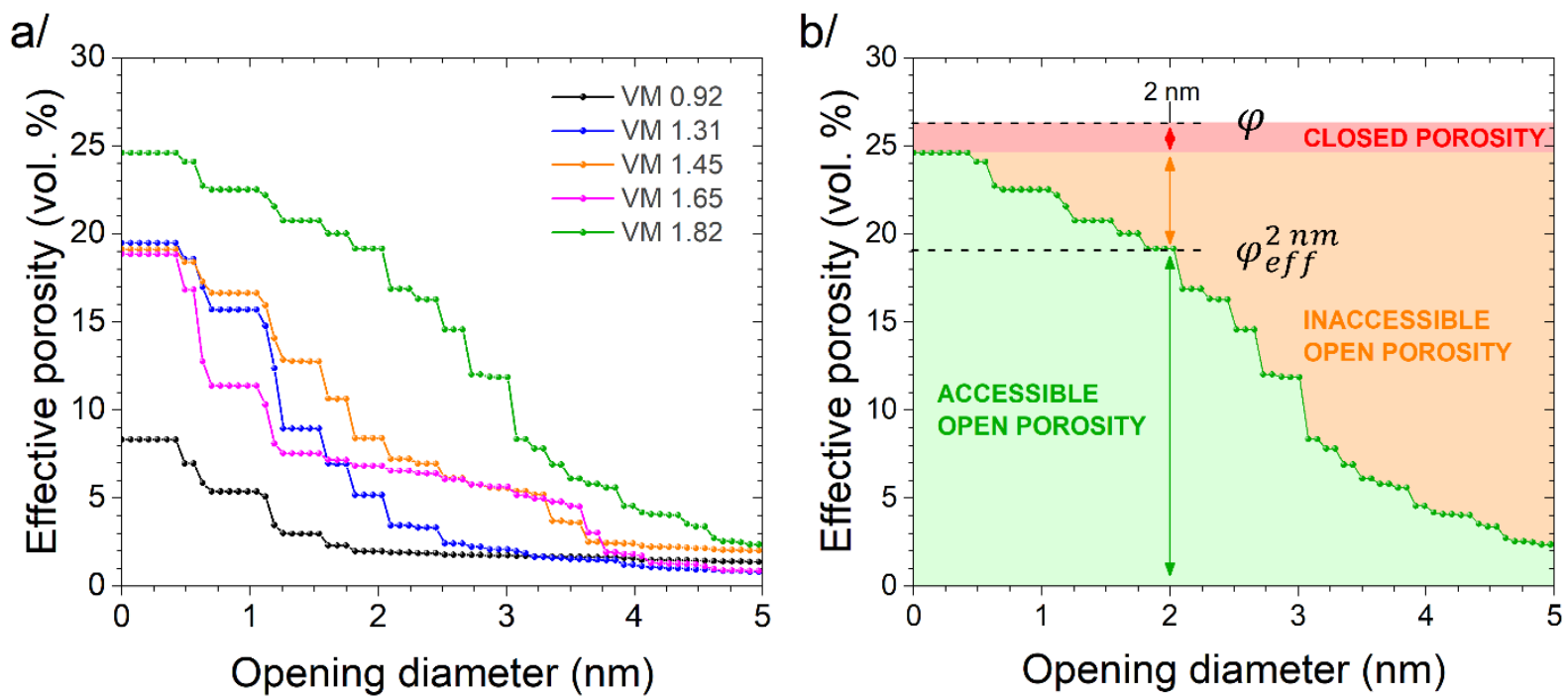

Figure 6. (a) Evaluation of the effective porosity of the organic porous networks with increasing opening diameter (or probe size). (b) Closed porosity, inaccessible porosity, and effective "open" porosities at $2 \mathrm{~nm}$ are reported on the percolation threshold of VM 1.82.

All the percolation curves recorded display a strong decay for opening diameters between 0.35 and $2 \mathrm{~nm}$ (Figure 6a). This means that the access to the porous network will be reduced for this molecular size range, and even more so for larger molecules. It will therefore affect the transport of alkane molecules in this size range, such as methane $\left(d_{\mathrm{CH}_{4}}=0.373 \mathrm{~nm}\right)$ or monomer $\left(d_{\mathrm{CH}_{2}}=0.395 \mathrm{~nm}\right)$ when dealing with n-hexane for example. ${ }^{10,58}$ This drop of accessibility is quite abrupt for the low maturity samples (VM 0.92 and VM 1.31) and slightly more progressive for VM 1.45, 1.65, and 1.82 (Figure 6a). Hence, the increase of pore volume with thermal maturation noted on this set of organic porous networks translates itself in terms of accessibility. 
Numerical studies have previously shown that hydrocarbon transport is dramatically impacted by the opening size of the porous networks. ${ }^{10}$ A transition in the transport regime generally occurs at pore diameters equivalent to five to six molecular diameters $(\sim 2 \mathrm{~nm}$, in the case of methane). Below this critical size, the transport is dominated by the interactions of the molecules with the pore walls, and the intermolecular interactions can be neglected. Molecules are in a diffusive regime, jumping randomly from a low-energy site to another at the pore surface. At this scale, a free volume approach can be used to describe the mass transport. ${ }^{10,12}$ When pores are larger than this limit (pores $>2 \mathrm{~nm}$ for methane), molecules recover some collective interactions, but adsorption on the pore walls still induce fluctuations in molecular density and the fluid viscosity depends on the local pore diameter. In that situation (at the mesoscale), molecules are both in diffusive and convective regimes. Finally, when the pores are sufficiently large (estimated at $\sim 50 \mathrm{~nm}$ in the case of methane), the adsorption of the molecules with the pore wall becomes negligible (purely convective regime) and the transport can be described by the Darcy's law, which is traditionally used to describe mass transport in porous media at the macroscale. The global, dimensional, and topological information gathered in the pore size range covered by electron tomography $(0.7<\varnothing<50 \mathrm{~nm})$ are therefore critical to study the transport of hydrocarbons in source rocks. From Figure 6, we can define the fraction of the pore volume accessible at $2 \mathrm{~nm}$ (Table S3). This fraction represents from 13.7 (VM 0.92) to $73.0 \%(\mathrm{VM} 1.82)$ of the organic porosity. We conclude that the governing mass transport phenomenon will, therefore, greatly evolve with the thermal maturation of the studied samples. The connectivity of such networks is another topological feature potentially affecting the fluid transport properties. As an attempt to evaluate the connectivity of those networks, we compute the average pore coordination number $Z$ from eq 5 , which is recognized as an important indicator of the mass transport properties of porous networks. ${ }^{33}$ The mean values of $Z$ are quite low and range from 3.25 (VM 1.31) to 3.31 (VM 1.82), see Table S3. These values 
indicate that, on average, the cavities are connected to three neighbors, and a marginal increase of $Z$ may be noted with the thermal maturation. However, the pore coordination number does not seem to be related to the effective porosity. In other words, it seems that the architecture of the pore networks does not evolve significantly with thermal maturity, unlike their size distribution, and it is the latter that influences accessibility and has a major impact on the evolution of transport properties.

Eventually, the tortuosity of the networks is evaluated by using random walkers, as it is often considered as a structural computation relevant to mimic transport properties. ${ }^{32}$ To do so, we generate a large number of random walkers $(150000)$ within the pore networks and record their free travel distance over 4500 iterations. Figure S3a schematically presents the free travel distance of a random walker between two points of the pore network, which, divided by the Euclidian distance between these two points, theoretically gives the random walker tortuosity $\tau_{r w}$. We plot these two distances for the ensemble of iterations performed and illustrate it in Figure S3b with two porous networks having the lowest (VM 0.92) and highest maturities (VM 1.82). The slope of these distributions should theoretically give their value of $\tau_{r w}$ but, it is obvious that many mathematical functions could be used to fit these curves. Instead, we chose to plot histograms of the relative frequency of tortuosity calculated for each iteration step (Figure S3c). Then, we fit these histograms with a lognormal function whose median value corresponds to $\tau_{r w}$ (Table S3).

Random walker tortuosity may be seen as the more rational value related to actual mass transport at this scale. ${ }^{34}$ Hydrocarbon molecules diffusing through the porous network are subject to numerous phenomena such as Brownian motion, slippage, friction, or physisorption along their diffusive path. With our random walker tracking approach, we determine $\tau_{r w}$ ranging from 1.37 to 2.76 (Table S3). While a general decrease trend of the tortuosity is sensed 
with thermal maturation in our data, an important variation from one tomogram to another within each VM sample is noted (see Table S3).

Organic-rich source rocks are heterogeneous by nature. Consequently, the results of the structural analyses performed at the scale of the electron tomograms are subjected to some caution regarding the representativity of the considered VM sample. Specific care was taken by selecting representative organic fragments from mosaics of BSE micrographs of the VM sample (Figure 1), before the acquisition of the electron tomograms. In addition, the organic matter composing the VM samples is known to be relatively homogeneous, as it mainly derives from marine microorganisms (type II kerogen). However, a compositional heterogeneity may be present within a VM sample and affect the geochemistry as well as the porous networks of the organic fragments. Such local heterogeneity may explain the variation in the global, dimensional, and topological information presented above.

Nonetheless, our results highlight a noticeable effect of thermal maturation of the VM formation on the organic pore volume and its accessibility. This geochemical control is illustrated in Figure $7 \mathrm{a}$ - c where the main thermal maturity indicators $\left(V_{R e q}\right.$, free $\mathrm{HC}$, and $\left.T R_{H I}\right)$ are plotted against three different effective porosity measurements $\varphi, \varphi_{\text {eff }}^{0.35 \mathrm{~nm}}$, and $\varphi_{\text {eff }}^{2 \mathrm{~nm}}$. One way of interpreting this evolution is to consider that the organic pore network of the thermally immature kerogen is populated by hydrocarbon molecules covering the walls of the carbon skeleton. During the thermal increase triggering the maturation, these molecules may either be progressively desorbed from the walls or undergo a secondary thermal cracking into "gas" molecules of decreasing size. Both processes will result in a progressive expulsion of the hydrocarbons molecules from the organic pore networks, which is sensed through the evolution of the free $\mathrm{HC}$ and transformation ratio by Rock-Eval pyrolysis (Table 1). This process substantially increases the aperture of the pore networks, hence increasing its accessibility. We further argue that this evolution affects the mass transport properties of the studied porous 
networks. In Figure 7d, we plot the evolution of the random walker tortuosity as a function of the effective porosity at $2 \mathrm{~nm}$ for all the studied tomograms. It allows us to visualize, from a purely geometrical perspective, the impact of the effective porosity on the transport of molecules. Here, the significant increase of $\tau_{r w}$ concomitant with the decrease in effective porosity can be explained by the trapping of random walkers in the cavities when their accessibility is low. This relationship roughly follows the thermal maturity trend except for the VM 1.65 sample, which shows three of the more inaccessible, and thus tortuous, pore networks. This variability pointed out along the morphological description, highlights the random and progressive character of geochemical processes affecting these natural materials.
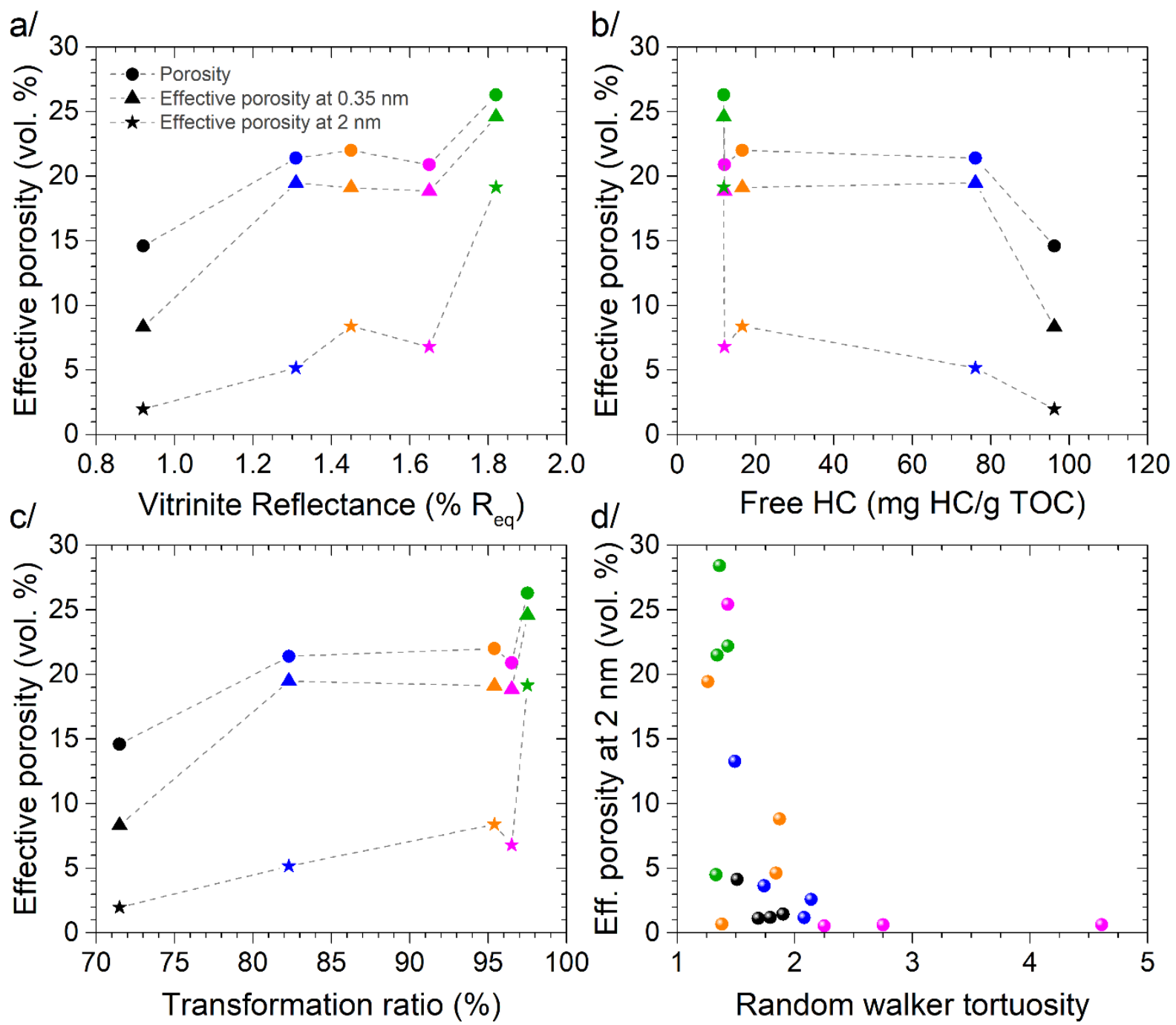
Figure 7. Impact of thermal maturity on the topology of the organic porous networks (the color code is similar to Figure 4). The mean effective porosities $\left(\varphi, \varphi_{\text {eff }}^{0.35} \mathrm{~nm}\right.$, and $\left.\varphi_{\text {eff }}^{2 \mathrm{~nm}}\right)$ are plotted as a function of (a) the Vitrinite Reflectance, (b) the free hydrocarbon content (free HC), and (c) the transformation ratio. (d) Impact of the effective porosity at $2 \mathrm{~nm}$ on the random walker tortuosity of the ensemble of tomograms.

\section{CONCLUSIONS}

The understanding of sorption and transport properties of confined hydrocarbons within the organic porous networks of kerogen is paramount to predict source rock production. As the chemical composition of kerogens changes during the thermal maturation induced by geological burial, its impact on the development of hosted organic nano- and mesopores must be properly addressed. We hence performed bright-field electron tomography on source rocks' organic matter of increasing thermal maturities. This approach allowed to numerically reconstruct the organic pores with sizes ranging from 0.7 to $50 \mathrm{~nm}$, representing from one-tenth to one-fourth of the total porosity. We document a general increase in pore volume during thermal maturation, but we also note a sample's internal dispersion of values. This dispersion results from the coexistence of mainly nano- and mesoporous locations within the heterogeneous organic porous networks of a considered sample. Nonetheless, the overall increase in pore volume is reflected in the evolution of the topological characteristics, such as the increasing accessibility to alkane molecules revealed by the evolution of the effective porosity $\varphi_{e f f}$. We interpret this evolution by a gradual release of hydrocarbon molecules covering the walls of the carbon skeleton, which substantially increases the volume of the pores and their opening. This process ultimately leads to a greater accessibility and thus strongly influences the mass transport properties. 
Our approach is purely geometric and needs to be complemented with fluid transport simulations to establish the actual effective transport properties of the organic pore networks. In nanopores, collective molecular interactions can be neglected due to the strong confinement, and molecules are in a diffusive regime. In mesopores (in between 2 and $50 \mathrm{~nm}$ ), collective interactions are partially recovered, and molecules are both diffusive and convective. Finally, in macropores $(>50 \mathrm{~nm})$, molecular diffusion is mainly convective and adsorption effects can be neglected. Determining diffusion coefficients in systems of about hundreds of nanometers or even micrometers is not yet possible by the sole use of full atom molecular dynamic simulations, due to the expensive computational time. Other methods such as lattice Boltzmann method (LBM) or computational fluid dynamics (CFD) cannot be directly used below $50 \mathrm{~nm}$ as the adsorption of the fluid on the pore walls is not considered and where parameters that originate from collective interactions as viscosity are meaningless. Atomistic simulations are thus the only way of integrating these effects as discussed in ref 59. This full-atom approach can then be upscaled using hybrid molecular dynamics and lattice Boltzmann method (LBM). ${ }^{59,60}$ These approaches would provide more insights into the governing transport regimes of hydrocarbon production from source rock formation.

\section{ASSOCIATED CONTENT}

\section{Supporting Information}

Details of the procedure for the organic geochemical characterization; unprocessed data obtained from the structural and topological description of the whole ensemble of tomograms (Table S1: global information, Table S2: morphological descriptors, Table S3: topological information); description of pore networks (Figure S1: examples of 3D reconstructions and evolution of dimensional information with thermal maturity; Figure S2: aperture size distribution; Figure S3: random walker tortuosity). 


\section{AUTHOR INFORMATION}

\section{Corresponding Author}

*Phone: +33(0)660 302 825. Fax:+33(0)491 418 916. Email: ferry@cinam.univ-mrs.fr

\section{Author Contributions}

The manuscript was written through contributions of all authors. All authors have given approval to the final version of the manuscript.

\section{Notes}

The authors declare no competing financial interest.

\section{ACKNOWLEDGMENTS}

The authors acknowledge funding from Total SA through the FASTER-Shale project, MITCNRS-AMU subaward N96416.

\section{REFERENCES}

(1) Kerr, R. A. Energy. Natural gas from shale bursts onto the scene. Science 2010, 328, $1624-1626$.

(2) Monteiro, P. J. M.; Rycroft, C. H.; Barenblatt, G. I. A mathematical model of fluid and gas flow in nanoporous media. Proc. Natl. Acad. Sci. U.S.A. 2012, 109, 20309-20313.

(3) Yethiraj, A.; Striolo, A. Fracking: what can physical chemistry offer? J. Phys. Chem. Lett. 2013, 4, 687-690.

(4) Patzek, T. W.; Male, F.; Marder, M. Gas production in the Barnett shale obeys a simple scaling theory. Proc. Natl. Acad. Sci. USA 2013, 110, 19731-19736. 
(5) Cueto-Felgueroso, L.; Juanes, R. Forecasting long-term gas production from shale. Proc. Natl. Acad. Sci. USA 2013, 110, 19660-19661.

(6) Vandenbroucke, M.; Largeau, C. Kerogen origin, evolution and structure. Org. Geochem. 2007, 38, 719-833.

(7) Tissot, B.; Welte, D. Petroleum Formation and Occurrence. Springer, Berlin, 1984, 702 p.

(8) Collell, J.; Ungerer, P.; Galliero, G.; Yiannourakou, M.; Montel, F.; Pujol, M. Molecular simulation of bulk organic matter in type II shales in the middle of the oil formation window. Energy Fuels 2014, 28, 7457-7466.

(9) Bousige, C.; Ghimbeu, C. M.; Vix-Guterl, C.; Pomerantz, A. E.; Suleimenova, A.; Vaughan, G.; Garbarino, G.; Feygenson, M.; Wildgruber, C.; Ulm, F.-J.; et al. Realistic molecular model of kerogen's nanostructure. Nat. Mater. 2016, 15, 576-582.

(10) Falk, K.; Coasne, B.; Pellenq, R.; Ulm, F.-J.; Bocquet, L. Subcontinuum mass transport of condensed hydrocarbons in nanoporous media. Nat. Commun. 2015, 6, 6949.

(11) Cihan, A.; Tokunaga, T. T.; Birkholzer, J. T. Adsorption and Capillary CondensationInduced Imbibition in Nanoporous Media. Langmuir 2019, 35, 9611-9621.

(12) Obliger, A.; Pellenq, R.; Ulm, F.-J.; Coasne, B. Free Volume Theory of Hydrocarbon Mixture Transport in Nanoporous Materials. J. Phys. Chem. Lett. 2016, 7, 3712-3717.

(13) Obliger, A.; Ulm, F.-J.; Pellenq, R. Impact of nanoporosity on hydrocarbon transport in shales' organic matter. Nano Lett. 2018, 18, 832-837.

(14) Obliger, A.; Valdenaire, P.-L.; Ulm, F.-J.; Pellenq, R. J.-M.; Leyssale, J.-M. Methane Diffusion in a Flexible Kerogen Matrix. J. Phys. Chem. B 2019, 123, 5635-5640.

(15) Lee, T.; Bocquet, L.; Coasne, B. Activated desorption at heterogeneous interfaces and long-time kinetics of hydrocarbon recovery from nanoporous media. Nat. Commun. 2016, 7 , 11890. 
(16) Louks, R. G.; Reed, R. M.; Ruppel, S. C.; Jarvie, D. M. Morphology, genesis, and distribution of nanometer-scale pores in siliceous mudstones of the Mississippian Barnett shale. J. Sediment. Res. 2009, 79, 848-861.

(17) Louks, R. G.; Reed, R. M. Scanning-electron-microscope petrographic evidence for distinguishing organic-matter pores associated with depositional organic matter versus migrated organic matter in mudrocks. GCAGS Journal 2014, 3, 51-60.

(18) Goral, J.; Panja, P.; Deo, M.; Andrew, M.; Linden, S.; Schwarz, J.-O.; Wiegmann, A. Confinement Effect on Porosity and Permeability of Shales. Sci Rep 2020, 10: 49.

(19) Cherfallot, G. J.; Levitz, P. E.; Michel, P.; Kohler, E.; Jestin, J.; Barré, L. Probing multiscale structure of mineral and nanoporous kerogen phase in organic-rich source rocks: Quantitative comparison of small-angle X-ray and neutron scattering. Energy \& Fuels 2020, 34, 9339-9354.

(20) Mastalerz, M.; He, L.; Melnichenko, Y. B.; Rupp, J. A. Porosity of coal and shale: Insights from gas adsorption and SANS/USANS techniques. Energy Fuels 2012, 26, 51095120.

(21) Clarkson, C. R.; Solano, N.; Bustin, R. M.; Bustin, A. M. M.; Chalmers, G. R. L.; He, L.; Melnichenko, Y. B.; Radliński, A. P.; Blach, T. P. Pore structure characterization of North American shale gas reservoirs using USANS/SANS, gas adsorption, and mercury intrusion. Fuel 2013, 103, 606-616.

(22) Gu, X.; et al. Quantification of organic porosity and water accessibility in Marcellus shale using neutron scattering. Energy Fuels 2016, 30, 4438-4449.

(23) Valenza, J. J.; Drenzek, N.; Marques, F.; Pagels, M.; Mastarlerz, M. Geochemical controls on shale microstructure. Geology 2013, 41, 611-614. 
(24) Wang, Y.; Zhu, Y.; Chen, S.; Li, W. Characteristics of the nanoscale pore structure in Northwestern hunan shale gas reservoirs using field emission scanning electron microscopy, high-pressure mercury intrusion, and gas adsorption. Energy Fuels 2014, 28, 945-955.

(25) Romero-Sarmiento, M.-F.; Ramiro-Ramirez, S.; Berthe, G.; Fleury, M.; Littke, R. Geochemical and petrophysical source rock characterization of the Vaca Muerta Formation, Argentina: Implications for unconventional petroleum resource estimations. Int. J. Coal Geol. 2017, 184, 27-41.

(26) Craddock, P. R.; Mosse, L.; Bernhardt, C.; Ortiz, A. C.; Tomassini, F. G.; Saldungaray, P.; Pomerantz, A. E. Characterization and range of kerogen properties in the Vaca Muerta formation, Neuquen basin, Argentina. Org. Geochem. 2019, 129, 42-44.

(27) Franck, J. Electron tomography: Methods for three-dimensional visualization of structures in the cell; Springer-Verlag US, 2005, 470 p.

(28) Biermans, E.; Molina, L.; Batenburg, K. J.; Bals, S.; Van Tendeloo, G. Measuring porosity at the nanoscale by quantitative electron tomography. Nano Lett. 2010, 10, 50145019.

(29) Bals, S.; Goris, B.; Altantzis, T.; Heidari, H.; Van Aert, S.; Van Tendeloo, G. Seeing and measuring in 3D with electrons. C. R. Physique 2014, 15, 140-150.

(30) Berthonneau, J.; Obliger, A.; Valdenaire, P.-L.; Grauby, O.; Ferry, D.; Chaudanson, D.; Levitz, P.; Kim, J. J.; Ulm, F.-J.; Pellenq, R. J.-M. Mesoscale structure, mechanics, and transport properties of source rocks' organic pore networks. Proc. Natl. Acad. Sci. USA 2018, $115,12365-12370$.

(31) Munch, B.; Holzer, L. Contradicting Geometrical Concepts in Pore Size Analysis Attained with Electron Microscopy and Mercury Intrusion. J. Am. Ceram. Soc. 2008, 91, 4059-4067. 
(32) Holzer, L.; Wiedenmann, D.; Munch, B.; Keller, L.; Prestat, M.; Gasser, P.; Robertson, I.; Grobety, B. The influence of constrictivity on the effective transport properties of porous layers in electrolysis and fuel cells. J. Mater. Sci. 2013, 48, 2934-2952.

(33) Stoeckel, D.; Kubel, C.; Hormann, K.; Holtzel, A.; Smarsly, B. M.; Tallarek, U. Morphological Analysis of Disordered Macroporous-Mesoporous Solids Based on Physical Reconstruction by Nanoscale Tomography. Langmuir 2014, 30, 9022-9027.

(34) Hormann, K.; Baranau, V.; Hlushkou, D.; Holtzel, A.; Tallarek, U. Topological analysis of non-granular, disordered porous media: determination of pore connectivity, pore coordination, and geometric tortuosity in physically reconstructed silica monoliths. New J. Chem. 2016, 40, 4187-4199.

(35) Penner, D.; Holzer, L. Characterization and Modelling of Structure and Transport Properties of Porous Ceramics. Process Eng. DKG 2018, 3, 27-32.

(36) Taylor, G. H.; Teichmüller, M.; Davis, A.; Diessel, C. F. K.; Littke, R.; Robert, P. Organic petrology: A new handbook incorporating some revised parts of Stach's textbook of coal petrology; Gebrüder Borntraeger: Berlin, Germany, 1998, 704 p.

(37) Behar, F.; Beaumont, V.; Penteado, H. L. De B. Rock-Eval 6 Technology: Performances and Developments. Oil \& Gas Sci. Tech. Rev. IFP. 2001, 56, 111-134.

(38) Ward, J.A. Kerogen density in the Marcellus shale. SPE Unconventional Gas Conf. Pittsburgh, USA. 2010, SPE 131767, 95-98.

(39) Williams, D. B.; Carter, C. B. The Transmission Electron Microscope; Springer-Verlag US, 1996.

(40) Bernard, S.; Wirth, R.; Schreiber, A.; Schultz, H.; Horsfield, B. Formation of nanoporous pyrobitumen residues during maturation of the Barnett shale (Fort Worth Basin). Int. J. Coal Geol. 2012, 103, 3-11. 
(41) Guo B.; Ma, L.; Tchelepi, H. A. Image-based micro-continuum model for gas flow in organic-rich shale rock. Adv.Water Resour. 2018, 122, 70-84.

(42) Hubler, M. H.; Gelb, J.; Ulm, F.-J. Microtexture Analysis of Gas Shale by XRM Imaging. J. Nanomech. Micromech. 2017, 7.

(43) Printemps, T. Debruitage, alignment et reconstruction 3D automatises en tomographie electronique : applications en sciences des matériaux. Thèse de Doctorat. Université Grenoble Alpes, 251 p., 2016.

(44) Hore, A.; Ziou, D. Image quality metrics: PSNR vs. SSIM. 2010 Int. Conf. on Pattern Recognition 2010, 2366-2369.

(45) Liao, P.-S.; Chen, T.-S.; Chung, P.-C. A Fast Algorithm for Multilevel Thresholding. J. Inf Sci. Eng. 2001, 17, 713-727.

(46) Iassonov, P.; Gebrenegus, T.; Tuller, M. Segmentation of X-ray computed tomography images of porous materials: A crucial step for characterization and quantitative analysis of pore structures, Water Resour. Res. 2009, 45, W09415.

(47) Garfi, G.; John, C.M.; Berg, S.; Kervor, S. The sensitivity of estimates of multiphase fluid and solid properties of porous rocks to image processing. Transport in Porous Media 2020, 131, 985-1005.

(48) Vicente, J.; Topin, F.; Daurelle, J.-V. Open Celled Material Structural Properties Measurement: From Morphology to Transport Properties. Mat. Trans. 2006, 47, 2195-2202. (49) Vicente, J.; Wyart, Y.; Moulin, P. Characterization (two-dimensional-threedimensional) of ceramic microfiltration membrane by synchrotron radiation: new and abraded membranes. J. Porous Media. 2013, 16, 537-545.

(50) Schneider, C. A.; Rasband, W. S.; Eliceiri, K. W. NIH Image to ImageJ: 25 years of image analysis. Nat. Methods 2012, 9, 671-675. 
(51) Pellenq, R. J.-M.; Levitz, P. Capillary condensation in a disordered mesoporous medium: A grand conical Monte Carlo study. Mol. Phys. 2002, 100, 2059-2077.

(52) Doube, M.; Klosowski, M. M.; Arganda-Carreras, I.; Cordelieres, F. P.; Dougherty, R. P.; Jackson, J. S.; Schmid, B.; Hutchinson, J. R.; Shefelbine, S. J. BoneJ: Free and extensible bone image analysis in ImageJ. Bone. 2010, 47, 1076-1079.

(53) Ben Clennell, M. Tortuosity: a guide through the maze. In: Lovell, M. A.; Harvey, P. K. (eds). Developments in Petrophysics; Geological Society Special Publications No. 122, 1997, 299-344.

(54) Matskova, N.; Pret, D.; Gaboreau, S.; Cosenza, P.; Brechon, R.; Gener, I.; Fialips, C. I.; Dubes, G.; Gelin, F. Toward a balance of pore size distribution in non-conventional hydrocarbon reservoirs: a combination of bulk techniques applied to comparable sub-samples localized by 3D X-ray $\mu$ tomography. URTeC 2017, URTEC-2689299-MS.

(55) Craddock, P. R.; Bake, K. D.; Pomerantz, A. E. Chemical, Molecular, and Microstructural Evolution of Kerogen during Thermal Maturation: Case Study from the Woodford Shale of Oklahoma. Energy Fuels 2018, 32, 4859-4872.

(56) Cheshire, S.; Craddock, P. R.; Xu, G.; Sauerer, B.; Pomerantz, A. E.; McCormick, D.; Abdallah, W. Assessing thermal maturity beyond the reaches of vitrinite reflectance and Rock-Eval pyrolysis: A case study from the Silurian Qusaiba formation. Int. J. Coal Geol. 2017, 180, 29-45.

(57) Obliger, A.; Valdenaire, P.-L.; Capit, N.; Ulm, F.-J.; Pellenq, R.J.-M.; Leysalle, J.-M. Poroelasticity of Methane-Loaded Mature and Immature Kerogen from Molecular Simulations. Langmuir 2018, 34, 13766-13780.

(58) Collel, J.; Galliero, G.; Vermorel, R.; Ungerer, P.; Yiannourakou, M.; Montel, F.; Pujol, M. Transport of multicomponent hydrocarbon mixtures in shale organic matter by molecular simulations. J. Phys. Chem. C 2015, 119, 22587-22595. 
(59) Magnin, Y.; Berthonneau, J.; Chanut, N.; Ferry, D.; Grauby, O.; Jorand, R.; Ulm, F.-J.; Chaput, E.; Pellenq, R. Hydrocarbon Diffusion in Mesoporous Carbon Materials: Implications for Unconventional Gas Recovery. ACS Appl. Nano Mater. 2020, 3, 7604-7610.

(60) Ning, Y.; He, S.; Liu, H.; Wang, H.; Qin, G. A rigorous upscaling procedure to predict macro-scale transport properties of natural gas in shales by coupling molecular dynamics with lattice Boltzmann method. SPE Annual Technical Conference and Exhibition 2016, 26-28 September, Dubai, UAE.

TABLE OF CONTENTS GRAPHIC

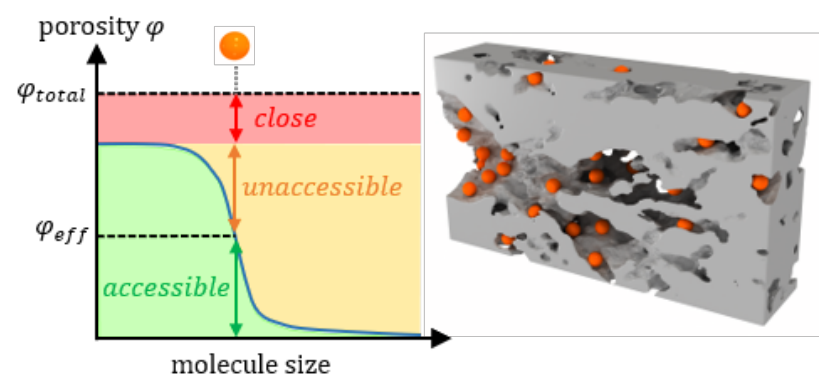




\section{Supporting information}

\section{Nanoscale accessible porosity as a key parameter}

\section{depicting the topological evolution of organic}

\section{porous networks}

Jeremie Berthonneau ${ }^{1}$, Olivier Grauby ${ }^{1}$, Isabelle C. Jolivet ${ }^{2}$, François Gelin², Nicolas

Chanut $^{3}$, Yann Magnin ${ }^{3}$, Roland J.-M. Pellenq ${ }^{1,3}$, and Daniel Ferry ${ }^{l, *}$

E-mail: ferry@cinam.univ-mrs.fr

${ }^{1}$ Aix-Marseille Univ, CNRS, CINaM, 13009 Marseille, France

${ }^{2}$ Total E\&P Research \& Development, CSTJF - Avenue Larribau, 64018 Pau Cedex, France

${ }^{3}$ MultiScale Materials Science for Energy and Environment, CNRS/MIT/Aix-Marseille University Joint Laboratory at Massachusetts Institute of Technology, Cambridge, Massachusetts 02139, USA

This file contains 8 pages, 3 figures and 3 tables. 


\section{Organic geochemistry}

The ensemble of 5 source rock samples from the Vaca Muerta (VM) formation (Neuquén basin, Argentina) was provided by Total SA. Their organic chemistry was evaluated by RockEval pyrolysis (Rock Eval 6, Vinci Technologies) and equivalent vitrinite reflectance (\% $\mathrm{R}_{\mathrm{eq}}$ ) using standard organic petrology technique described in detail in ref. 1. As the Vaca Muerta source rock does not contain vitrinite, the bitumen reflectance was measured optically and translated into equivalent vitrinite reflectance based on the relationship established in ref. 2 and validated on our set of samples in ref. 3. The resulting vitrinite reflectance values range from 0.92 to $1.82 \% \mathrm{R}_{\mathrm{eq}}$ and evidences the evolution of thermal maturity of the studied samples. The organic solid density was deduced form the relation $\rho_{s}=0.342 \times R_{e q}+0.972$, defined in ref. 4. The different peaks recorded along the pyrograms (not shown) and the total organic carbon (TOC) content were used to compute the fraction of free hydrocarbons (Free HC $=\mathrm{S} 1 / \mathrm{TOC} \mathrm{x}$ $100)$, hydrogen index $(\mathrm{HI}=\mathrm{S} 2 / \mathrm{TOC} x 100)$, and oxygen index $(\mathrm{OI}=\mathrm{S} 3 / \mathrm{TOC} x 100)$. The reader is referred to ref. 5 for the procedure of interpretation of Rock Eval pyrograms. The projection of the hydrogen indexes allows for the estimation of an "onset" hydrogen index $\left(\mathrm{HI}_{0}\right)$ of the source rock formation, which is used to compute the transformation ratio $\left(\mathrm{TR}_{\mathrm{HI}}\right)$ of the organic matter, evolving here from 71.5 to $97.5 \%$. Our set of source rock samples therefore covers a significant range of thermal maturation experienced by the Vaca Muerta formation. 
Table S1. Global information of the organic pore networks.

\begin{tabular}{|c|c|c|c|c|c|}
\hline $\begin{array}{l}\text { Tomogram } \\
\#\end{array}$ & $\begin{array}{l}\text { Vitrinite } \\
\text { reflectance } \\
\left(\% \mathrm{R}_{\mathrm{eq}}\right)\end{array}$ & $\begin{array}{l}\text { Specific Pore } \\
\text { Volume, } V_{p} \\
\left(\mathrm{~cm}^{3} / \mathrm{g}\right)\end{array}$ & $\begin{array}{l}\text { Porosity, } \\
\varphi \\
\text { (vol. \%) }\end{array}$ & $\begin{array}{l}\text { Mean chord } \\
\text { length, }\langle l\rangle \\
(\mathrm{nm})\end{array}$ & $\begin{array}{l}\text { Specific } \\
\text { surface area, } \\
S_{s p} \\
\left(\mathrm{~m}^{2} / \mathrm{g}\right)\end{array}$ \\
\hline 1 & 0.92 & 0.170 & 18.0 & 3.8 & 179.9 \\
\hline 2 & 0.92 & 0.138 & 15.1 & 4.9 & 112.4 \\
\hline 3 & 0.92 & 0.080 & 9.3 & 4.9 & 64.3 \\
\hline 4 & 0.92 & 0.147 & 16.0 & 3.5 & 170.8 \\
\hline Mean value & 0.92 & 0.134 & 14.6 & 4.3 & 131.9 \\
\hline 1 & 1.31 & 0.196 & 21.8 & 3.7 & 211.4 \\
\hline 2 & 1.31 & 0.200 & 22.1 & 7.6 & 105.2 \\
\hline 3 & 1.31 & 0.150 & 17.5 & 4.2 & 142.3 \\
\hline 4 & 1.31 & 0.223 & 24.0 & 5.4 & 166.1 \\
\hline Mean value & 1.31 & 0.192 & 21.4 & 5.2 & 156.3 \\
\hline 1 & 1.45 & 0.206 & 23.2 & 12.1 & 67.8 \\
\hline 2 & 1.45 & 0.285 & 29.5 & 3.5 & 325.9 \\
\hline 3 & 1.45 & 0.065 & 8.7 & 6.7 & 38.5 \\
\hline 4 & 1.45 & 0.245 & 26.5 & 3.6 & 270.4 \\
\hline Mean value & 1.45 & 0.200 & 22.0 & 6.5 & 175.7 \\
\hline 1 & 1.65 & 0.263 & 28.8 & 7.8 & 134.3 \\
\hline 2 & 1.65 & 0.096 & 12.8 & 4.0 & 96.0 \\
\hline 3 & 1.65 & 0.187 & 22.4 & 2.2 & 342.5 \\
\hline 4 & 1.65 & 0.156 & 19.4 & 3.1 & 200.6 \\
\hline Mean value & 1.65 & 0.176 & 20.9 & 4.3 & 193.4 \\
\hline 1 & 1.82 & 0.249 & 28.3 & 6.4 & 154.1 \\
\hline 2 & 1.82 & 0.136 & 17.8 & 6.1 & 89.1 \\
\hline 3 & 1.82 & 0.301 & 32.4 & 7.6 & 158.5 \\
\hline 4 & 1.82 & 0.226 & 26.5 & 8.4 & 108.2 \\
\hline Mean value & 1.82 & 0.228 & 26.3 & 7.1 & 127.5 \\
\hline
\end{tabular}




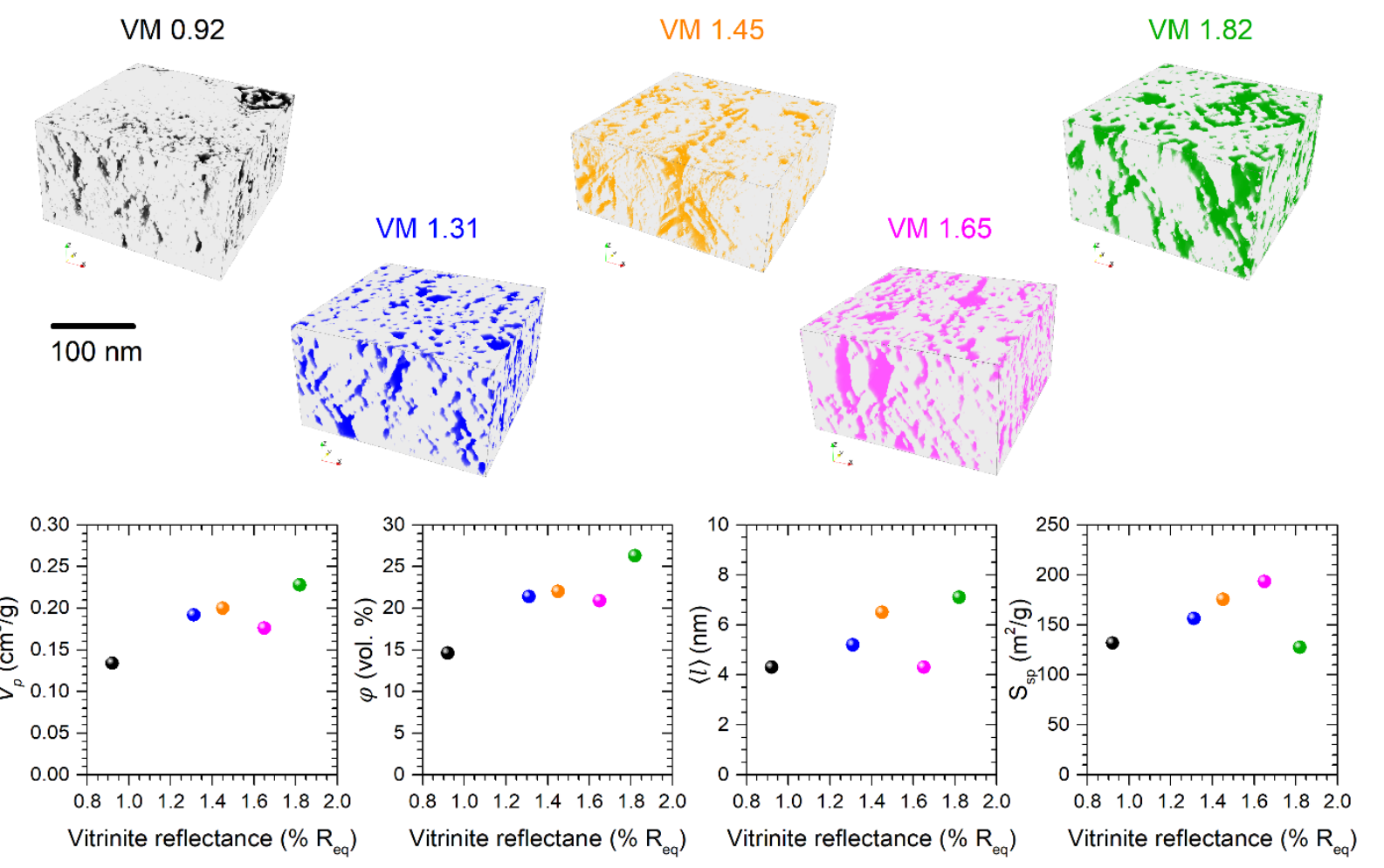

Figure S1. Examples of 3D reconstructions (top) of the organic porous networks (in color) from the Vaca Muerta samples together with the evolution of the mean dimensional information as a function of the increasing thermal maturity (bottom).

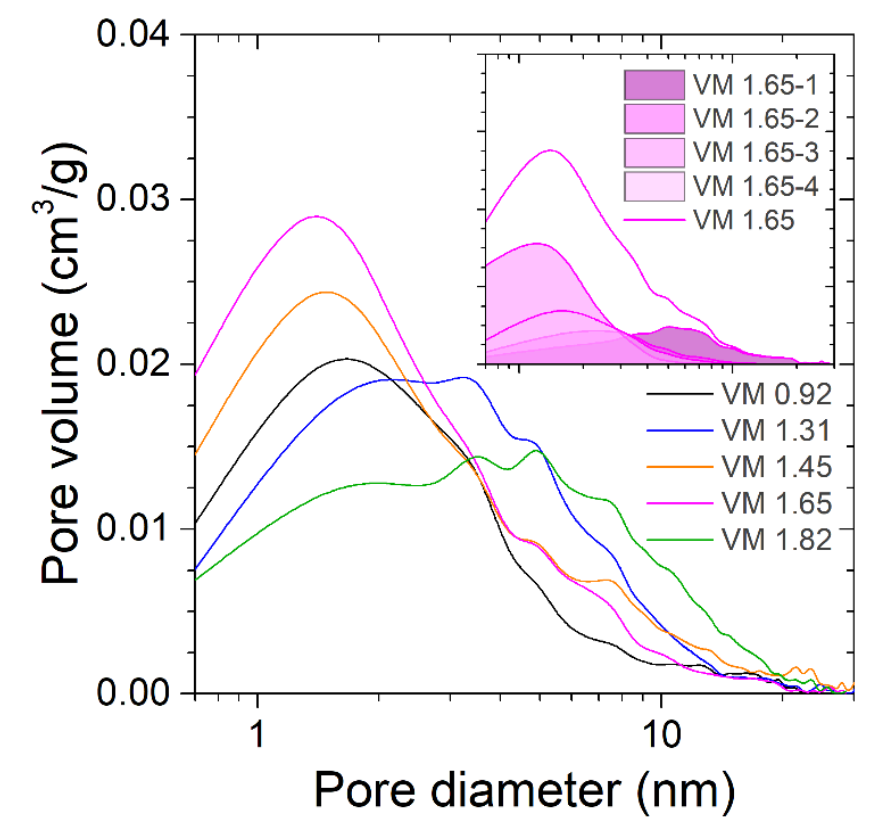

Figure S2. Pore size distributions of the VM samples from the statistical analysis of the tomograms (aperture size distribution). Inset: aperture sizes distribution of each tomograms of VM 1.65 (color filled area), the summation of these PSDs produced the general aperture size distribution (solid line). 
Table S2. Morphological descriptors of the organic pore networks.

\begin{tabular}{|c|c|c|c|c|c|}
\hline $\begin{array}{l}\text { Tomogram } \\
\# \\
-\end{array}$ & $\begin{array}{l}\text { Vitrinite } \\
\text { reflectance } \\
\left(\% \mathrm{R}_{\mathrm{eq}}\right)\end{array}$ & $\begin{array}{l}\text { Specific Mesopore } \\
\text { volume, } V_{\text {meso }} \\
\left(\mathrm{cm}^{3} / \mathrm{g}\right)\end{array}$ & $\begin{array}{l}\text { Aperture } \\
\text { size, } h \\
(\mathrm{~nm})\end{array}$ & $\begin{array}{l}\text { Cavity } \\
\text { size, } H \\
(\mathrm{~nm})\end{array}$ & $\begin{array}{l}\text { Constriction, } \\
\beta \\
-\end{array}$ \\
\hline 1 & 0.92 & 0.097 & 3.7 & 11.2 & 0.33 \\
\hline 2 & 0.92 & 0.098 & 6.8 & 17.0 & 0.40 \\
\hline 3 & 0.92 & 0.062 & 5.3 & 12.5 & 0.42 \\
\hline 4 & 0.92 & 0.076 & 4.9 & 15.4 & 0.32 \\
\hline Mean value & 0.92 & 0.083 & 5.2 & 14.0 & 0.37 \\
\hline 1 & 1.31 & 0.112 & 3.5 & 10.6 & 0.33 \\
\hline 2 & 1.31 & 0.185 & 8.6 & 17.7 & 0.49 \\
\hline 3 & 1.31 & 0.102 & 4.4 & 11.5 & 0.38 \\
\hline 4 & 1.31 & 0.183 & 5.4 & 12.1 & 0.45 \\
\hline Mean value & 1.31 & 0.146 & 5.5 & 13.0 & 0.41 \\
\hline 1 & 1.45 & 0.199 & 13.9 & 29.1 & 0.48 \\
\hline 2 & 1.45 & 0.143 & 3.5 & 13.0 & 0.27 \\
\hline 3 & 1.45 & 0.055 & 9.0 & 21.1 & 0.43 \\
\hline 4 & 1.45 & 0.130 & 3.6 & 12.4 & 0.29 \\
\hline Mean value & 1.45 & 0.132 & 7.5 & 18.9 & 0.37 \\
\hline 1 & 1.65 & 0.239 & 8.1 & 17.5 & 0.46 \\
\hline 2 & 1.65 & 0.062 & 3.7 & 10.4 & 0.36 \\
\hline 3 & 1.65 & 0.034 & 1.7 & 14.5 & 0.12 \\
\hline 4 & 1.65 & 0.071 & 3.0 & 10.3 & 0.29 \\
\hline Mean value & 1.65 & 0.102 & 4.1 & 13.2 & 0.31 \\
\hline 1 & 1.82 & 0.197 & 6.8 & 16.9 & 0.40 \\
\hline 2 & 1.82 & 0.113 & 6.4 & 15.1 & 0.42 \\
\hline 3 & 1.82 & 0.264 & 7.9 & 18.1 & 0.44 \\
\hline 4 & 1.82 & 0.206 & 8.6 & 19.4 & 0.44 \\
\hline Mean value & 1.82 & 0.195 & 7.4 & 17.4 & 0.43 \\
\hline
\end{tabular}



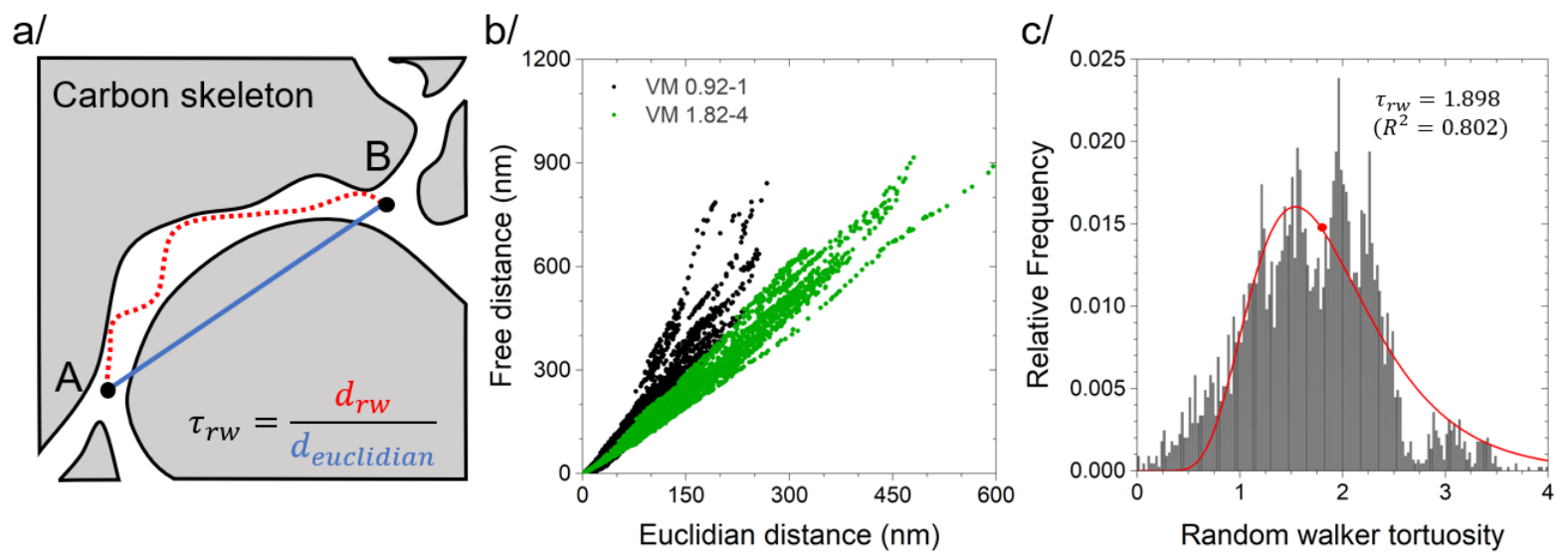

Figure S3. Random walker tortuosity $\tau_{r w}$ measurements performed on the tomograms. a/ Schematic of the free distance (red dashed line) travelled by a random walker between two points $(\mathrm{A}, \mathrm{B})$ in a pore and the corresponding Euclidian distance (blue solid line) between these two points. b/ Random walker free travel distance plotted against the corresponding Euclidian distances for VM 0.92-1 and VM 1.82-4. c/ Relative frequency histogram of the random walker tortuosities for VM 0.92-1. The median value of the lognormal fit represents the random walker tortuosities $\tau_{r w}$ reported in Table S3. 
Table S3. Topological information of the organic pore networks.

\begin{tabular}{|c|c|c|c|c|c|}
\hline $\begin{array}{l}\text { Tomogram } \\
\# \\
-\end{array}$ & $\begin{array}{l}\text { Vitrinite } \\
\text { reflectance } \\
\left(\% \mathrm{R}_{\mathrm{eq}}\right)\end{array}$ & $\begin{array}{l}\varphi_{\text {eff }}^{0.35 \mathrm{~nm}} \\
(\%)\end{array}$ & $\begin{array}{l}\varphi_{\text {eff }}^{2 \mathrm{~nm}} \\
(\%)\end{array}$ & $\begin{array}{l}\text { Pore } \\
\text { connectivity, } Z \\
\text { - }\end{array}$ & $\begin{array}{l}\text { Random walker } \\
\text { tortuosity, } \tau_{r w} \\
\text { - }\end{array}$ \\
\hline 1 & 0.92 & 16.5 & 1.5 & 3.25 & 1.90 \\
\hline 2 & 0.92 & 5.2 & 4.1 & 3.27 & 1.51 \\
\hline 3 & 0.92 & 2.4 & 1.1 & 3.22 & 1.69 \\
\hline 4 & 0.92 & 9.1 & 1.2 & 3.31 & 1.79 \\
\hline Mean value & 0.92 & 8.3 & 2.0 & 3.26 & 1.72 \\
\hline 1 & 1.31 & 20.6 & 2.6 & 3.29 & 2.14 \\
\hline 2 & 1.31 & 20.6 & 13.3 & 3.18 & 1.49 \\
\hline 3 & 1.31 & 13.9 & 1.2 & 3.25 & 2.08 \\
\hline 4 & 1.31 & 22.9 & 3.6 & 3.26 & 1.74 \\
\hline Mean value & 1.31 & 19.5 & 5.2 & 3.25 & 1.86 \\
\hline 1 & 1.45 & 20.6 & 19.4 & 3.16 & 1.26 \\
\hline 2 & 1.45 & 28.7 & 8.8 & 3.37 & 1.87 \\
\hline 3 & 1.45 & 1.5 & 0.7 & 3.23 & 1.38 \\
\hline 4 & 1.45 & 25.6 & 4.6 & 3.38 & 1.84 \\
\hline Mean value & 1.45 & 19.1 & 8.4 & 3.29 & 1.58 \\
\hline 1 & 1.65 & 28.3 & 25.4 & 3.24 & 1.43 \\
\hline 2 & 1.65 & 8.6 & 0.6 & 3.24 & 2.25 \\
\hline 3 & 1.65 & 21.2 & 0.6 & 3.39 & 4.61 \\
\hline 4 & 1.65 & 17.2 & 0.6 & 3.26 & 2.75 \\
\hline Mean value & 1.65 & 18.8 & 6.8 & 3.28 & 2.76 \\
\hline 1 & 1.82 & 27.3 & 21.5 & 3.34 & 1.34 \\
\hline 2 & 1.82 & 14.2 & 4.5 & 3.29 & 1.33 \\
\hline 3 & 1.82 & 31.7 & 28.4 & 3.33 & 1.36 \\
\hline 4 & 1.82 & 25.2 & 22.2 & 3.27 & 1.43 \\
\hline Mean value & 1.82 & 24.6 & 19.2 & 3.31 & 1.37 \\
\hline
\end{tabular}




\section{REFERENCES}

(1) Taylor, G. H.; Teichmüller, M.; Davis, A.; Diessel, C. F. K.; Littke, R.; Robert, P. Organic petrology: A new handbook incorporating some revised parts of Stach's textbook of coal petrology; Gebrüder Borntraeger: Berlin, Germany, 1998.

(2) Jacob, H. Classification, structure, genesis and practical importance of natural solid oil bitumen ("migrabitumen"). Int. J. Coal Geol. 1989, 11, 65-79.

(3) Mei, M.; Burnham, A., K.; Schoellkopf, N.; Wendebourg, J.; Gelin, F. Modeling petroleum generation, retention, and expulsion from the Vaca Muerta Formation, Neuquen Basin, Argentina: Part I. integrating compositional kinetics and basin modeling. Mar. Pet. Jeol. 2021, 123, 104743.

(4) Ward, J.A. Kerogen density in the Marcellus shale. SPE Unconventional Gas Conf. Pittsburgh, USA, 2010.

(5) Behar, F.; Beaumont, V.; Penteado, H. L. De B. Rock-Eval 6 Technology: Performances and Developments. Oil \& Gas Sci. Tech. Rev. IFP. 2001, 56, 111-134. 